\title{
A Right Time to Give: Beyond Saving Time in Automated Conditional Donations
}

Nicola J. Bidwell, International University of Management, Namibia and Northumbria University, United Kingdom, nic.bidwell@gmail.com

Chris Elsden, Institute of Design Informatics, University of Edinburgh, United Kingdom, celsden@ed.ac.uk

Ludwig Trotter, School of Computing \& Communications Lancaster University, United Kingdom, I.k.trotter@lancaster.ac.uk

Josh Hallwright, Oxfam Australia, Australia, joshh@oxfam.org.au

Sadie Moore, Oxfam Australia, Australia, sadie_moore@hotmail.com

Kate Jeite-Delbridge, Oxfam Australia, Australia, katedelbridge@gmail.com

Mike Harding, School of Computing and Communications Lancaster University, United Kingdom, m.harding@lancaster.ac.uk

Peter Shaw, School of Computing and Communications Lancaster University, United Kingdom, p.shaw@lancaster.ac.uk

Nigel Davies, School of Computing and Communications Lancaster University, United Kingdom, nigel@comp.lancs.ac.uk

Chris Speed, Institute of Design Informatics, University of Edinburgh, United Kingdom, c.speed@ed.ac.uk

John Vines, Institute of Design Informatics, University of Edinburgh, United Kingdom, john.vines@ed.ac.uk

\begin{abstract}
Smart Donations is a blockchain-based platform that enables users to program and set conditions on charitable donations. Users set up contracts to donate in response to real-world events, e.g., whenever an earthquake is detected or an activist tweets about refugees. We designed Smart donations with Oxfam Australia, trialled it over 8-weeks with 86 people and qualitatively analysed questionnaires and interviews about their experiences. Temporal qualities emerge when automation enforces conditions that determine when donations are made. These contributed to participants' sense of immediacy in donating to humanitarian crises, ongoing involvement while awaiting conditions to be met, and awareness of events that are usually unconscious. We suggest that automation can reveal diverse temporal registers, in real-world phenomena, sociality, morality and everyday life, which contribute to experiencing a 'right time' to donate. Thus, we recommend adopting a sensitivity to right time in designing for multiple temporalities in FinTech more generally.
\end{abstract}

CCS CONCEPTS

- Human-centered computing Interaction design Empirical studies in interaction design

Keywords

Temporal Design, Blockchain, FinTech, Philanthropic Informatics, Right time, Temporal marginalisation, Financialisation of natural disasters, Automation, Programmable donations

\section{Introduction}

The focus on efficiency, convenience and saving time in visions of new data-driven technologies is often critiqued in $\mathrm{HCl}$ research on Philanthropic Informatics and financial technologies (FinTech) [27, $\underline{32}, \underline{39}, \underline{44}$. Studies repeatedly observe the diverse and situated nuances of philanthropic work [33] and the artful and creative ways that people manage and socially interact around digital and analogue money [72, 94]. Complex relations also emerge in automated, data-driven personal transactions; for instance, communication and self-expression appear as important as financial efficacy when people programme rules and intentions using a mobile banking app [18]. In this paper we explore people's experiences in programming conditions that determine their donations to charity. We suggest temporal qualities, that emerge when automation enforces these conditions, shape experiences of giving that are not limited to saving time.

We analyse user experiences in a trial of a new platform that enabled participants to program and set conditions for charitable donations. Unlike giving ad-hoc in response to a fundraiser or regularly via a monthly bank transfer, donations are automatically driven by data about specific phenomena. Smart Donations, a blockchain-based platform, offers users 'contracts' that donate money to certain causes in response to real-world events. For example, participants could donate when an earthquake is detected or whenever an activist tweets about refugees. If the conditions the user sets are not met by the time the contract expires funds are returned to them. Our 8-week trial of Smart Donations produced several distinct contributions, including the technical implementation [이], platform governance, interface design and the choice of data to drive donations. This paper focuses on the temporal qualities of users' experiences that emerged when automation, based on data-driven transactions, enforces their financial intentions. Programming a smart donation does not simply mediate if a donation is made, but when it is 
made. Temporality is a well-recognised feature of people's experiences of technology [73], and designers are increasingly urged to recognise "pluritemporality" [66] and that time is relational and differential (e.g. [48, $\underline{75}$ ]. However, existing data-driven technologies neglect diverse experiences of time and little prior work has explored temporality in the context of FinTech or Philanthropic Informatics.

Rather than prioritizing efficiency, Smart Donations enforces exactly when transactions occur. Participants in our trial set up 'smart contracts', on a mobile app, to donate to various programmes run by Oxfam Australia. The contracts used data about relevant real-world phenomena to determine if and when to release pledged funds to a specified programme. In addition to temporal features integral to blockchain technology, contracts were triggered at different thresholds and frequencies and over different durations, based on the conditions that participants set. We surveyed 86 participants before and after the trial, collected analytics of their app usage, interviewed 15 of them afterward, and then analysed their experiences of the temporalities that emerged in the trial. Some felt an immediacy in the tie between their donations to humanitarian crisis and data about phenomena that cause them; some felt an ongoing involvement in causes after setting criteria; and many became more aware of the social, political, geological and meteorological phenomena that triggered donations.

Participants interviewed in our prior study about the concept of 'programmable donations' speculated about the challenges of negotiating temporality and predicting and waiting for contract conditions to be met [21]. They suggested that while upfront commitments and rational links between donations and events might feel worthy, the 'warm glow' felt in donating would be delayed or absent, and the uncertainty about a conditional donation occuring may induce anxiety. Our analysis of deploying a real-world trial of the fully functional Smart Donations app, however, uncovered other relations between felt-experiences, moralreasoning and the temporalities of users who pledge donations, of phenomena that create circumstances that need support and of a charity's response. Thus, we suggest the relations that emerge in using Smart Donations contribute to different experiences of a right time to give.

The term, right time, was first introduced to $\mathrm{HCl}$ by Aboriginal authors to describe the appropriate timing of cultural practices when ecological, ancestral, metaphysical, meteorological and other phenomena converge [10], however non-Aboriginal people also relate to it $[\underline{89}, 99]$. We use the term to speak to the multiple ways people experience and interpret time and reconcile different temporal orders. Right time involves sensing and responding appropriately to the timing of events and may help us design to support an awareness of diverse temporalities in environmental and social phenomena, emotions and moral reasoning. Thus, we extend literature about time in $\mathrm{HCl}$ and the way algorithms and data-driven and automated technologies reify particular temporal arrangements [75]. We contribute empirical insights about the effects of synchronising donating with real-world events on felt-experience, including senses of immediacy in contributing to crisis response and ongoing involvement in situations far-away, and awareness of events that are usually unconscious. Our analysis highlights, firstly, the role of automation in juxtaposing diverse temporal patterns and, secondly, how data-driven automation in philanthropy contributes to experiences and reasoning about right times to give, beyond productivity or efficiency.

\section{Related work}

Participants' experiences of automation, in the trial, reveal different "temporal registers" or general rhythms [38] in real-world phenomena, in sociality, morality and everyday life. Their experiences inspired us to reflect on how reconciling different registers yields a right time to give. Thus, we begin by anchoring our perspective in the diverse literature on temporality in $\mathrm{HCl}$, and then connect this to automation and studies in Philanthropic Informatics and money, on which our research builds.

\subsection{Right Time in $\mathrm{HCl}$}

In media studies, Bucher proposes that by sorting, filtering, ranking, curating content and aggregating data on people's interactions, algorithms personalise a "right-time" for a user to experience media [12]. She compares this right-time to 'kairos', a Greek concept that refers to an opportune time to say or do something or an unpredictable moment that presents an occasion that must be seized. Kairos has inspired work in $\mathrm{HCl}$; the Kairoscope, for example, is an automatic scheduling system that aims to reduce users' stress about when exactly events will happen by both optimizing their time use and assigning precise times only as appointments approach [51]. Kairos contrasts with the 'right time' described by Aboriginal authors in $\mathrm{HCl}$, who undertake their cultural practices when certain tangible and intangible circumstances converge [10]. Non-Aboriginal people also associate right time with states when an external temporal regime is not imposed, such as sensing the moment to lower the heat in cooking a familiar recipe or "me-time, where I can be as by myself" [99].

Like Taylor et al, we interpret right time as "a set of converging circumstances that constitute "the time" for happenings to take place" and recognise that practices unfold in ways that are particular to a situation [89]. Importantly, we account for the way Aboriginal authors relate right time to being aware of ecological and moral, as well as personal and social, cues by observing the circumstances involved [10]. This differs from Bucher's understanding of right-time as a "personalized moment instigated by aggregated individuals, and fuelled by the business models of platforms" [12]. We propose feelings and reasonings that relate to right times to give go beyond optimizing time use and are experienced through the intersections and juxtapositions of diverse temporal patterns and orders. Thus, next, we describe how digital devices are often framed by less nuanced beliefs about saving time, by doing things faster and more efficiently. Then we refer to some, of many, studies to suggest that optimising time in certain ways discounts the value of adapting to different temporalities. 


\subsubsection{Saving Time in a Pluritemporal World.}

Our experiences of time are simultaneously quantitative, objective, subjective, situated and socially constructed, and we assign many meanings to these experiences [66]. Negotiating such "pluritemporality" [66] and multiple temporal orders and registers is vital to collaboration. Consider, for instance, digital humanitarians distributed across many countries applying their various expertise to respond to disasters [58]. They devote effort not only to managing many temporal orders in incoming streams of information, metadata structures and systems that encode and display time in various ways but also to reconciling diverse personal and cultural representations and experiences of time [58]. Despite this diversity, technological innovation and digital devices are often framed in a "discourse of speed" that emphasises progress and busyness [95]. Technologies and modern cultures of instantaneity [48] and hyper-productivity [95] have co-evolved, and are critiqued for affecting our well-being, and senses of rush and lack of control $[46,81]$. Such critique has prompted approaches to Temporal Designs [75] that encourage more flexible and inclusive engagements with time, a more "human experience of time" and reflection or experiences over longer durations linked to organic rhythms or different metaphors (e.g. [24, $\underline{31}, \underline{51}, \underline{60}, \underline{61}, \underline{62]) . ~ W e ~ o f t e n ~ a s s u m e ~ d e t e r m i n i s m ~ i n ~ t h e ~}$ way technologies disconnect people from 'natural' lifestyles [99], however, we have also honed skills to coordinate our activities with different measures and tempos [36, 63] and often only notice incongruence when one set of temporal registers intrude on other obligations and desires in our lives [9].

Certainly, our experience of "digital time", as we interact with technology, differs from chronological time and the social and biological rhythms of everyday life (e.g. [99]). For instance, the flow of continually changing, but constantly accessible, digital information contributes to the "condition of immediacy" [48], in which we interact with asynchronous information as if we are in the same temporal register as it. This includes, for instance, the experience of "nowness", when we treat social media posts as if they report on current events and imagine them in an unfolding story with a past and future [34]. Technology use, social conventions and temporal design entwine to uphold experiences of immediacy and nowness. In fact, while they seem distracting, Lindley [48] suggests that many technologies do not set a pace of interaction but flexibly fit into our rhythms and afford an experience that is both interruptible and expandable into unanticipated gaps in schedules (e.g. [37]). Yet, priorities for productivity and efficiency often foster a need to fill this "plastic time" meaningfully [99].

\subsubsection{Beyond Efficiency: Awareness in Reconciling Temporalities.}

It's common to perceive the pace of modern life as accelerating, however studies show that we do not have less leisure time or more things to do than people 80 years ago (see: [48]). Rather, we make more effort to coordinate our daily lives because work patterns are more heterogenous and there are fewer fixed institutional events, such as standard mealtimes or 'paydays'. We can feel overloaded and busier by trying to stay "on the same page" in "collective time" [99] with our family and friends [48, 99], such as when we enact our togetherness across the temporal fractures in our lives in an endless trace of WhatsApp messages [64]. Our temporalities are interwoven and interdependent, and some cultural practices more than others explicitly express the inherent inseparability of time and human relationships. Work in ICTD, for instance, observes that design abstractions that prioritise schedules and punctuality disrupt local temporal orders and registers in some societies (e.g. [9]). Yet participation in the same temporal orders is distributed unevenly according to a society's power relations [80]. Some rhythms are prioritised in divisions of labour, for instance those working on early morning or night shifts support those who work '9-to-5'. Tensions emerge when algorithms designed to match supply and demand, such as timebanks and on-demand service platforms, do not account for the way time is differential and the extra work some people must do to coordinate with others (e.g. [13, 83]). In fact, automated on-demand services contribute to, and normalise temporal orders that marginalise 'just-in-time' workers. Consider how Uber has only slightly increased the overall volume of taxi journeys [30] but significantly increased complaints to non-Uber taxis [97].

In response to their marginalisation, platform workers opportunistically reconstruct their temporalities when trying to meet the demands imposed or behave subversively $[13,53]$. At peak hours, for instance, auto-rickshaw drivers in India ignore pick-up requests from an Uber-like app because riders renege on bookings when drivers do not reach them fast enough, often without cancelling [1]. Automation can undermine the transient awareness that enables people to coordinate. Compare automated ridesharing platforms, for instance, with the uninterrupted tempo achieved in Namibia's self-organising, shared taxi system, where drivers' and riders' mutual awareness enables drivers to keep all the seats in their taxis full and riders to hail an affordable ride to their destinations from the roadside [41].

Indeed, successful collaboration depends on looking beyond individual people's efficiency and reconciling the many rhythms of different roles, jobs, identities, life-stages, organizations and infrastructures $[6, \underline{38}, \underline{45}, \underline{55}, \underline{78}$. Jackson et al.'s study of scientific collaboration highlights the work people perform to align to temporal registers in nature and society, such as circadian, seasonal or perennial rhythms and episodic events [38]. The sense of right time amidst all this temporal diversity is less about optimising time and more about noticing, and adapting to, the many orders and registers involved.

\subsection{Time, Money and Philanthropy}

All our interactions with money have temporal qualities whether spending to a budget, saving for the future or splurging bonus income, and FinTech and banking applications often track and predict personal spending, over time, to support our co-ordination of money [39, 47]. However, "moneywork" [72], or the appropriate ordering of different aspects of financial interactions that make transactions technically and socially effective, is oriented by more than efficiency, speed and economic rationales [39, 94]. While being able to pay at a particular moment enables successful transactions, we manage our money in "artful" and "creative" ways [94] and the right time to pay is deeply situated. For instance, members of low-income households carefully delay or prioritise paying bills to maintain their livelihoods and reputations $[65, \underline{91}$. Enforcing a commitment to pay through technologies, such as 
blockchain-based contracts (e.g. [56, 86]), must then account for diverse factors. Thus, next, we introduce literature on some of the consequences of automation and conditionality on people's financial practices before outlining some temporal issues in philanthropic informatics.

\subsubsection{Blockchain and Automated, Conditional Financial Interactions.}

Rules and conditions have long been associated with different forms of "special monies" [44, 100], such as designating cash for specific purposes in household budgets or restricting how food stamps can be spent. Recent attention has turned to programming money and financial systems for certain uses and automatically enforcing payment [18, 21]. We are becoming accustomed to an increasing range of interactive and digital representations of money such as virtual currencies, mobile money, cryptocurrencies [17, 23, $\underline{40}, \underline{43}, \underline{96]}$; to financial services that depend upon transactional data [59]; and smart, autonomous and "self-driving" money that adheres to sets of automated rules and procedures [52] and is already used in financial trading [29, $\underline{50]}$. Complex relations emerge between people and money in automated, conditional, data-driven transactions. Consider how agency and expression are as important as efficiency when users of a mobile banking app programme rules and intentions into their money, such as putting some into a savings account whenever it rains [18]. Consider also how conflicts emerge between users' immediate and more analytical thoughts about payment and the consequences of their choices when using a financially autonomous coffee machine [87]. Building systems such as coffee machines and Smart Donations on a blockchain makes automated rules and conditions immutable. Written in 'smart contracts', the code governing these conditions is hard-wired; the consensus process and distribution of blockchain technologies ensure that protocols and transaction histories are transparent and not easily changed $[19, \underline{77]}$. This immutability is important to trusting a financial escrow's operation but also entails a predetermined approach. Prior research on interacting with blockchain technologies has focused on trust (e.g. [도, $\underline{42}, \underline{49}, \underline{79}]$ ), conditionality (e.g. [21, $\underline{76}, \underline{86]})$, contracting (e.g. [56, 22]) and governance (e.g. [14, 57]); however, little has examined the unique temporal experiences made possible when blockchains and escrows preserve and enforce past intentions. Blockchains have other potential implications for temporal realities that motivate exploring user experiences with them in relation to real-world events. 'Blocktime', or the time that it takes a certain number of blocks to confirm, is a separate time schema from the time of events and temporal registers that shape fiat currencies. Manipulating the differential between these schema, by configuring the conversion metric or the blockchain event trajectory, can ensure they reinforce each other or create more time by arbitrage [84]. Thus, contracts could include blocktime offsets, for example, to increase the competitive advantage of algorithms that financialize real-world events (e.g. [29]). This prompts considering the values in relation to blockchain and time.

\subsubsection{Philanthropic Informatics, Data-driven Giving and Time.}

$\mathrm{HCl}$ research on "charitable technologies" [28] encompasses organisational management [11, 33], delivering aid programmes [3,

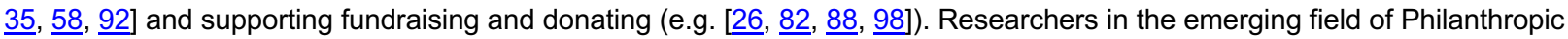
Informatics [92] have also argued that increased datafication and metricization can disempower non-profit organizations [11], neglect the situated care entailed by their work [33] and, meanwhile, mediate donors', stakeholders' and beneficiaries' values $[20,93]$. Extending this field to consider data-driven technologies in fundraising from individual donors, a co-speculative interview study examined the potential of a 'programmable donations' service [21]. The study proposed that identifying data and conditions suited to trigger a donation will present challenges but did not explore the temporal qualities that might emerge.

Indeed, given the improvements to efficiency and speed envisioned by Philanthropic IT [32], and often sought for responses to humanitarian disasters, studies on the temporality of technology-mediated giving are strikingly absent. Nonetheless other research shows temporality affects the complex feelings and morality associated with giving. Empirical studies suggest eight key mechanisms drive us to give to charity, ranging from awareness of need and altruism, through to reputation and psychological benefits [7], and that ambiguities arise when we are asked to give, for instance, faced by a fundraiser we might dislike being asked or just dislike saying no [4]. Ambiguities and moral contradictions are also affected by elapsed time, between deciding in advance to give and then actually giving. Delaying the transaction of funds, after committing to give, can avoid the guilt of saying no, but also reduce the immediate feeling of a 'warm glow'. While some people who pledge may renege later, others will give more and the timing of pre-emptive thanks, after pledging, also affects if and how much people give [4]. In contrast with studies of temporal effects on pledging, Smart Donations prevents reneging because it holds funds 'in escrow' after they are pledged and releases them only when the contract ends. Thus, enforcing commitments and automating conditions introduces novel temporal situations for charitable giving and opportunities to explore the experience of donations configured to occur at a specific time.

\section{Smart donations and Time}

Smart Donations was developed as part our team's research about blockchain technologies in the so called 'first mile' of charitable giving, rather than for coordination, transparency or trust in charities (e.g. [15]). It uses an automated escrow to determine if and when users make donations, not to track, record or disburse donations [주 $\underline{16}, \underline{74}$. Some of the authors conceptualised the platform in 2018, while establishing a partnership with Oxfam Australia and undertook fieldwork and stakeholder engagement to explore its potential for fundraising. Employees of the charity felt that conditional, automated giving could attract new donors to certain causes and sought to explore new user experiences of the many different conditions that donors could set-up, not just match donor's money to a specific need. While not the only way to deploy conditional giving, blockchains offer an enhanced level of trust because they support distributed actors in transparently enforcing a set of rules and governance of each transaction [90]. Thus, subsequently we worked together to create a broad range of content to implement in a trial. 


\subsection{The Smart Donations Platform}

The reference architecture for Smart Donations comprises three layers: (i) A smart contract compatible blockchain, (ii) off-chain components, and (iii) and a mobile app (see: [90] for technical details). The distributed ledger, the blockchain, provides the runtime environment for smart contracts, containing the logic for the value exchange and escrow and. For the trial we operationalised the Smart Donations on a private, permissionless Ethereum network. External 'data providers', or oracles, connect to the system via a secured Representational State Transfer API (RestAPI). The off-chain systems, for privacy-sensitive user data of donors and beneficiaries, are hosted on traditional databases with the charities involved and we implemented their functionalities as custom Python backend and SQL databases. The mobile phone application supports the two most popular smartphone operating systems using cross-platform technology (Apache Cordova and lonic 4).

The mobile app presents templates for 'contracts' that allow users to set up conditions to trigger a donation from funds that are held 'in escrow' and released to the charity only when the conditions are met. Every template is a dedicated 'smart contract' deployed on the blockchain that records the donor's pledges. The blockchain assures the terms of the escrow cannot be changed. By choosing a pre-set 'smart plan' or creating a custom contract, users can pledge funds providing there are sufficient in their personal wallet. After 'signing' the contract and a 5-min 'cool-down' period, when a commitment can be withdrawn, the pledge is being 'sealed'. Once sealed, a donation cannot be altered and will be automatically issued if the set conditions were met. Each contract expires after a defined duration, configured as 1-14 days in the trial (Tables 1 to $\underline{5}$ ), and returns any remaining funds to the user's wallet. App notifications inform users in real-time when their contract 'seals', fulfills or expires, and when conditions are met.

An 'active' contract relies upon data from an authorised external data provider to ensure its conditions are met, for instance we used the US Geological Society (USGS) for Earthquake Insurance contracts (Table 4). The contract releases a predetermined amount of funds when a condition is met, such as when an earthquake above the threshold magnitude occurs in a selected place (e.g. Figure 1). 'One-off' donations release all funds in the escrow if the condition is met, whereas 'recurring' donations release funds whenever the condition is met until either none remain in the escrow or the contract expires. While the return of funds underpins Smart Donation's conditionality, configuring how much and when donations are made has more effect on a contract's temporality. The exchange of fiat money (i.e. AUD) a digital asset (i.e. a crypto- currency or a crypto token) is crucial in order to manage, transfer and seal funds in self-governing digital trust funds underwritten by smart contracts on the blockchain. To avoid interfacing with payment systems, we provided digital vouchers to participants in our trial, which we managed in a dedicated token contract following the EIP-20 / ERC-20 standard. We settled the balance after the trial with research funds.

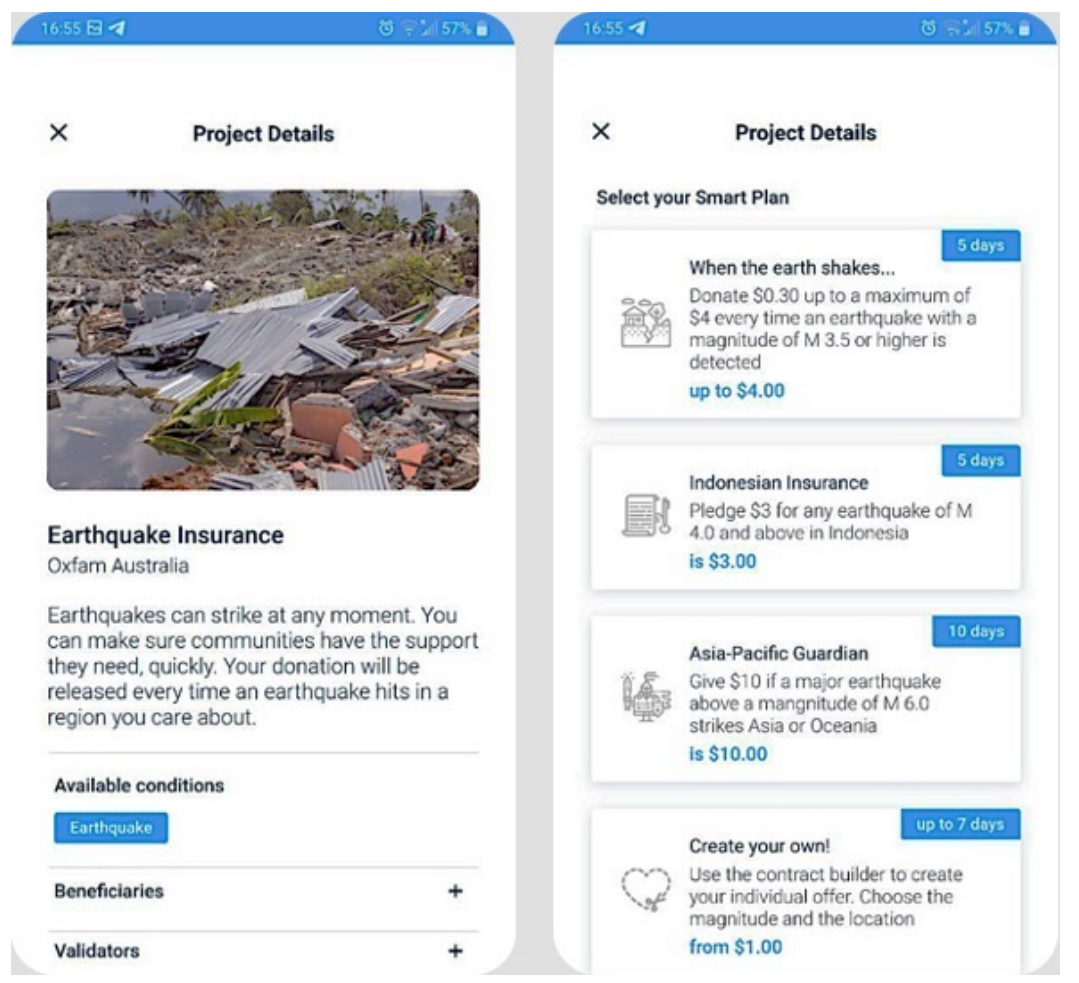

Figure 1: Screenshots of one of the contracts in the Smart Donations app. Each project included key information and links about the donation and options to configure particular pre-set or custom conditions. 


\section{$\leftarrow$ \\ Contract Builder \\ Earthquake Insurance \\ Set your conditions}

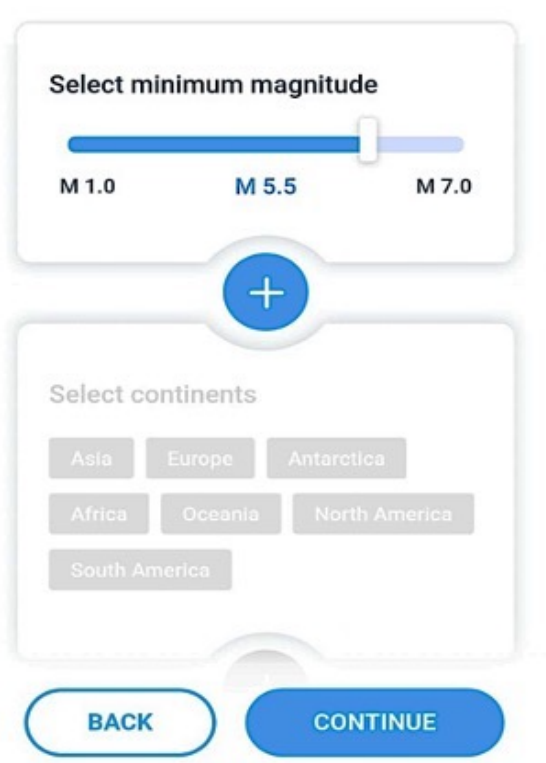

Your offer

You are comitting a maximum of $\$ 2.00$ in the smart donation escrow. $\$ 1.00$ will be donated to International Crisis Fund, an earthquake with a magnitude of M 6.0 or greater strikes Asia or Oceania., validated by U.S. Geological Survey.

\section{Validation}

The trusted validator for this contract is: U.S. Geological Survey. You will receive a notification when your contract has been validated. Once the contract is validated, the funds will be transferred to the recipient defined in the contract. You will receive a notification when these funds are withdrawn.

\section{Expiration}

If the contract expires in 7 day(s) before its conditions were met or if the contract is declined, the funds will be returned to your account. You can either renew the contract, enter into a new contract, or withdraw the funds completely.

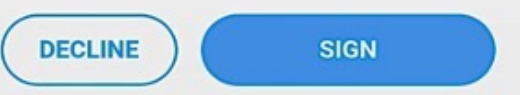

Figure 2: Two screenshots showing set-up of a custom smart donation using the contract builder. Donors can specify conditions for a donation, and then sign the donation.

\subsection{Causes, Contracts and Time}

We devoted effort to identifying reliable, manageable and sensible data sources to represent real-world events and provide users with choices between many different contracts. In designing contracts, we asked: does this data make sense, relate sufficiently to the cause, convey a story that compels giving to a cause, is it consistent, reliable and predictable, and how likely will conditions be met during trial? We linked contracts to events with varied rates of occurrence but did not explicitly design contracts to produce certain temporal experiences. Rather, temporal features emerged because of the deployment timelines and the data used.

Shine a Light on Refugees contracts highlighted issues confronting refugees, and the role of online activism and public discourse. Donations were directed to Oxfam Australia's refugee projects [71], which protect and advocate for protecting and helping refugees. Users could select from three smart plans or create a custom contract (Table 1). Contracts automatically pulled from prominent politicians' and activists' Twitter accounts and parsed tweets according to a balanced set of keywords and hashtags associated with refugees and suggested by Oxfam Australia. Retweets were not included. When notified that a contract had donated, users could view the tweet. Contracts received data sporadically, tied to media about political events, however, by interacting with Twitter users could, potentially, influence the frequency of the source data.

Keep Families Together contracts directed donations to Oxfam Australia's ongoing campaign to prevent separating refugee families when they arrive in Australia and was an opportunity to explore linking Smart Donations into activism work, where fundraising is difficult. Users could select from three smart plans (Table 2). Contracts were triggered by signatures on a petition [70], thus donors added funds into the campaign as it gained momentum, could track the progress of the petition and promote it themselves. Keep Families Together contracts were triggered far fewer times than other contracts (Table 6).

Fight Climate Change contracts highlighted the increased potential for extreme temperatures and donations were directed to Oxfam Australia's Climate Change projects [67]. Users could select from three smart plans (Table 3). Contracts received frequent updates of reliable data from Australia's Bureau of Meteorology (BOM). Contracts, however, could be triggered only once a day as a daily temperature high was compared to historical records. The recurring contracts reflect sustained periods of warm weather and the one-off contract was an extreme event.. 
Table 1: The data used by Shine a Light on Refugees contracts

\begin{tabular}{|c|c|c|c|c|}
\hline Data Source & \multicolumn{4}{|c|}{ Twitter, www.twitter.com } \\
\hline $\begin{array}{l}\text { Update } \\
\text { frequency }\end{array}$ & \multicolumn{4}{|c|}{15 minutes } \\
\hline Data & \multicolumn{4}{|c|}{$\begin{array}{l}\text { Accounts of politicians/activists: Peter Dutton, Nick McKim, Behrouz Boochani, Rex Patrick, Kristina Kenally; Keywords: } \\
\text { letthemstay, hometoBilo, refugees, migrants, Medevac, border protection, Manus Island, Nauru }\end{array}$} \\
\hline Contract builder & \multicolumn{4}{|c|}{$\begin{array}{l}\text { Select a single account of politicians/activists (required) and give every time they tweet or if they use one or multiple } \\
\text { keywords (optional). Set duration (up to } 7 \text { days) }\end{array}$} \\
\hline Smart plan & Donation & $\begin{array}{l}\text { Max } \\
\text { donation }\end{array}$ & Trigger - any account tweets about: & $\begin{array}{l}\text { Max. } \\
\text { duration }\end{array}$ \\
\hline Hear the debate & $\$ 0.20$ & $\$ 2$ & "refugees or migration" & 5 days \\
\hline Safe harbor & $\$ 0.30$ & $\$ 3$ & "border protection" & 5 days \\
\hline $\begin{array}{l}\text { Mention } \\
\text { Medevac }\end{array}$ & $\$ 0.50$ & $\$ 5$ & the Medevac Bill & 5 days \\
\hline
\end{tabular}

Table 2: The data used by Keep Families Together contracts

\begin{tabular}{|c|c|c|c|c|}
\hline Data Source & \multicolumn{4}{|c|}{ Oxfam Australia's petition } \\
\hline Update frequency & \multicolumn{4}{|c|}{15 minutes } \\
\hline Data & \multicolumn{4}{|c|}{ Number of new signatures; total number of signatures } \\
\hline \multicolumn{5}{|l|}{ No contract builder } \\
\hline Smart plan & Donation & Max donation & Trigger - Signatures of & Max. duration \\
\hline Every voice counts & $50 c$ & $\$ 2$ & 100 newly added & 7 days \\
\hline Hit the target & $\$ 1$ & $\$ 5$ & 500 newly added & 10 days \\
\hline Celebrating milestones & one-off & $\$ 5$ & 10,000 in total & 10 days \\
\hline
\end{tabular}

Table 3: The data used by Fight Climate Change contracts

\begin{tabular}{|c|c|c|c|c|}
\hline Data Source & \multicolumn{4}{|c|}{ Bureau of Meteorology (BOM), www.bom.gov.au/ } \\
\hline Update frequency & \multicolumn{4}{|c|}{15 minutes } \\
\hline Data & \multirow{2}{*}{\multicolumn{4}{|c|}{ Daily temperatures in Brisbane, Melbourne and Sydney; record high temperatures Sydney }} \\
\hline No contract builder & & & & \\
\hline Smart plan & Donation & Max donation & Trigger - A temperature that exceeds: & $\begin{array}{l}\text { Max. } \\
\text { duration }\end{array}$ \\
\hline November Heatwave & $40 c$ & $\$ 4$ & $32 \mathrm{C}$ in Brisbane in a day & 10 days \\
\hline Melting in Melbourne & $50 \mathrm{c}$ & $\$ 2.50$ & $27 \mathrm{C}$ in Melbourne in a day & 5 days \\
\hline Too hot to handle & one-off & $\$ 3$ & 38.9C in Sydney - November 2018 record & 5 days \\
\hline
\end{tabular}

Earthquake Insurance contracts were about communities around the globe affected by earthquakes. Donations were directed to Oxfam Australia's International Crisis Fund [69], which coordinates emergency responses to natural or man-made disasters. Users could select from three smart plans (Table 1) or create a custom contract (Figure 2, Table 4). We pushed data, aggregated from a global network, by the USGS's public API. Contracts received data frequently, as earthquakes can occur at any time and are reported almost immediately. Contracts with higher magnitude conditions were less likely to be triggered but contracts set for low magnitudes were often triggered by smaller earthquakes and aftershocks and exhausted funds before the contract expired.

Cyclone Protector contracts triggered donations as tropical cyclones form over the Pacific. Donations were directed equally to Oxfam Australia's International Crisis Fund and Disaster Risk Reduction projects [68], which develop the resilience of communities to mitigate the impacts of hazards, such as earthquakes, droughts and cyclones. Users could select from three smart plans or create a custom contract (Table 5). Author-3 manually input data about the formation, development, path and status of cyclones into the platform from the Global Disaster and Coordination System (GDACS). As the trial took place at the start of the cyclone season, we expected contracts to trigger rarely but have extended duration 
Table 4: The data used by Earthquake Insurance contracts

\begin{tabular}{|c|c|c|c|c|}
\hline Data Source & \multicolumn{4}{|c|}{ US Geological Society (USGS), www.usgs.gov/ } \\
\hline Update frequency & \multicolumn{4}{|c|}{15 minutes } \\
\hline Data & \multicolumn{4}{|c|}{ Magnitude of earthquakes M1 to M7 (Richter scale); continent (all), country (all) } \\
\hline Contract builder & \multicolumn{4}{|c|}{$\begin{array}{l}\text { Select magnitude between M1 to M7 (anywhere on earth); set one or more continents (optional); filter one or } \\
\text { more countries within the selected continents (optional); set duration (up to } 7 \text { days) }\end{array}$} \\
\hline Smart plan & Donation & $\begin{array}{l}\text { Max } \\
\text { donation }\end{array}$ & Trigger - An earthquake of: & $\begin{array}{l}\text { Max. } \\
\text { duration }\end{array}$ \\
\hline When the earth shakes & $30 c$ & $\$ 4$ & M3.5 or above, detected anywhere on earth & 5 days \\
\hline Indonesia Insurance & $\$ 3$ & $\$ 5$ & M4 or above detected in Indonesia & 5 days \\
\hline Asia-Pacific Guardian & one-off & $\$ 10$ & M6 or above detected in Asia or Oceania & 10 days \\
\hline
\end{tabular}

Table 5: The data used by Cyclone Protector contracts

\begin{tabular}{|c|c|c|c|c|}
\hline Data Source & \multicolumn{4}{|c|}{ The Global Disaster and Coordination System (GDACS), www.gdacs.org } \\
\hline Update frequency & \multicolumn{4}{|c|}{12 hours } \\
\hline Data & \multicolumn{4}{|c|}{$\begin{array}{l}\text { Event type: cyclone forms or makes landfall; location: Western Pacific, Fiji, Cook Islands, Kiribati, Marshall Islands, } \\
\text { Micronesia, Naru, Niue, Palau, Papua New Guinea, Samoa, Solomon Islands, Tonga, Tuvalu, Vanuatu; number of } \\
\text { people affected }\end{array}$} \\
\hline Contract builder & \multicolumn{4}{|c|}{$\begin{array}{l}\text { Select event type (required); set location (optional); set number of people affected }(0-100,0000) \text {; set duration (up to } 7 \\
\text { days) }\end{array}$} \\
\hline Smart plan & Donation & $\begin{array}{l}\text { Max } \\
\text { donation }\end{array}$ & Trigger - A cyclone that: & $\begin{array}{l}\text { Max. } \\
\text { duration }\end{array}$ \\
\hline Sound the alarm & $\$ 1$ & $\$ 3$ & Forms anywhere in the Western Pacific & 5 days \\
\hline Cyclone relief & one-off & $\$ 3$ & Makes landfall in Vanuatu & 5 days \\
\hline Pacific Defender & one-off & $\$ 5$ & Exposes more than 100,000 people in the Western Pacific & 5 days \\
\hline
\end{tabular}

\section{The Trial: Methods}

We trialled Smart Donations in October and November 2019 across both iOS and Android operating systems. Oxfam Australia supported the recruitment of participants through direct email invitations and social media posts that directed interested people to a website (https://oxchain.lancaster.ac.uk/). The website described the app and the trial, including that participants needed to be aged 18 years or over and own a smartphone, but did not need to be tech savvy or support Oxfam Australia. It explained that we would give participants $\$ 10.00$ from research funds to donate during the trial to Oxfam Australia's campaigns or be redeemed as a shopping voucher after the trial.

After participants had registered and completed an online ethical consent form and pre-trial questionnaire, we sent them a link to download the app and asked them to use the app however they liked. We provided remote support, but few participants requested help. Participants trialled the app for between 34 to 61 days, depending on when they began and when their final contracts expired. We onboarded participants in batches from October $8^{\text {th }}$ for 62 Android users and October $27^{\text {th }}$ for 60 iPhone users, because the iOS App Store delayed verifying the app. We gave participants vouchers to add $\$ 10.00$ to their wallet at the start of the trial, another $\$ 10$ midway (October $31^{\text {st }}$ ) to 18 Android users who had already committed all of their funds, and then $\$ 10$ to all active participants two weeks before trial's end. We stopped accepting new contracts from November $24^{\text {th }}($ Figure 3$)$. The app included three contracts to start: Earthquake Insurance Keep Families Together and Shine a Light on Refugees; and on November $8^{\text {th }}$ we added Fight Climate Change and Cyclone Protector contracts.

We captured analytic data about participants' usage of the app and then surveyed participants using a post-trial questionnaire. Within a month, after preliminary analysis of responses to the post-trial questionnaire, we (Author-1) interviewed 15 participants on Zoom or telephonically for an hour. Interviews were semi-structured, driven by a topic guide and explored participants' motivations, experiences, feelings and opinions in the trial. Participants often looked at the app to assist recall and referred to temporal issues although no question specifically asked about time. Interviews were recorded and transcribed by an external human.

\subsection{Participants}

Of the 123 participants invited to install the app, 93 downloaded it and 81 used it until the end of the trial. A total of 53 women, 30 men and three participants of undisclosed or third gender (86) completed an online pre-trial questionnaire and actively used the app at least two sessions. They ranged in age from 18 to over 70 years old, but most (68\%) were aged 25 to 49 years, $42 \%$ 
were aged 30 to 39 years. Over $90 \%$ of participants had university educations, and half postgraduate diplomas or degrees. They tended to be in middle to high-middle income groups, with over half earning between $\$ 37,000$ and $\$ 145,000$ per year.

Participants were fairly evenly spread across a range of occupations, although nearly $10 \%$ said they worked in the third sector in non-profit/aid organisations and over $10 \%$ worked in IT. About half were familiar (32) or very knowledgeable (6) about blockchain technologies, and about half (43) had heard about blockchain. About a quarter of participants had not heard about cryptocurrencies but a few had bought (9), sold (5) or purchased with cryptocurrency (3). Participation was not geographically restricted thus, whilst most participants were Australian or had close connections with Australia, several lived overseas during the trial. The 29 women, 21 men and two participants of undisclosed gender who completed the post-trial questionnaire did not significantly differ in any characteristics of the full set who trailed the app, except a few more were employed in the humanitarian sector and/or worked in IT-related jobs. Fewer women (5) than men (10) participated in interviews, and $40 \%$ of participants interviewed were currently worked in the humanitarian sector, and $20 \%$ worked in IT, in or outside of the charity sector. All elements of the trial and study were assessed and received ethical approval from the research ethics committee at the institution leading the deployment.

\subsection{Analysis}

Three of us coded, open-ended questions in the post-trial questionnaires and interviews, which produced nearly 170 open codes, and some preliminary themes. In parallel, we applied descriptive and inferential statistics to the responses of participants who completed the trial, to closed questions in pre- and post-trial questionnaires.

The quantitative analyses prompted examining some themes in more detail, including temporality, thus we selectively coded all references to temporality in interviews and responses to open-ended questions in the post-trial questionnaires, yielding about 40 codes, grouped in ten themes. Unless explicitly mentioned, the quotes we present in our findings are from interviews. For readability, and to demonstrate data inclusion, we include participant identifiers only for block quotes.

\section{$5 \quad$ Findings}

We begin our account of the ways temporality shaped participants' experiences in using Smart Donations by outlining some qualities of the trial that promoted saving time. Subsequent sections describe, however, that tempos that reconcile the app and participants' lives are about more than conveniently donating. Participants had different experiences of temporality when engaging with the app and varied perspectives on the diverse temporalities of themselves, other people and external phenomena. Complicated moral and emotional trajectories emerged when they set up contracts, awaited their conditions to be met, and when donations were or were not made. These experiences entwined with feeling connected to real-world phenomena and helping the charity's response. Thus, our findings suggest the app created opportunities for participants to experience right times to donate.

\subsection{Saving Time in a 21st Century Trial}

In recruiting participants, Oxfam Australia called for "trailblazers". Participants reflected this framing of innovation when they described the trial as "modern" or "21st century" and the app as "cutting edge". Only a few were sceptical about a need to automate donations, such as referring to blockchain technologies as a "buzzword". It can take 30 seconds to process a transaction on the blockchain and, with an average time at just over 5-minutes, setting up contracts is slower than making some online payments. Yet participants associated the app with speed and efficiency in terms becoming quicky aware that something happened in the world and improving the efficacy of donating for users who are "time poor". For instance, one said he would want to:

... set it up for the year and have my contracts be a year-long and then I presume that over the year it would all be used up... [ ] Because that's just me wanting to be efficient. - Interview P125

We set short durations to ensure participants could try different contracts during the trial which affected the tempos of interaction and whether conditions were met. Over the 8 week trial, participants claimed a total of $\$ 1,640.00$ AUD in vouchers and made 567 pledges of $\$ A U 1,964.40$, of which $34 \%$ were issued because conditions were met (Table 6 ). Each participant made on average 7 pledges, and all but one donated the funds remaining at the trial's end. Many said that spending a few minutes setting up new contracts was appropriate, for example:

... where I am, people are playing with [phones] on the train every day and it's not a problem to spend three minutes to set up your donation the way you like... So at the moment I think it's fine, as long as it's easy enough and it's playful to a degree. - Interview P139 
Table 6: The rates of selection of Smart Donation contracts by participants (\% of total contracts) and issuing donations (when conditions were met) and total and average amount pledged

\begin{tabular}{lllllll}
\hline Cause & $\begin{array}{l}\text { Launch } \\
\text { date }\end{array}$ & $\begin{array}{l}\text { Contracts } \\
\text { offered }\end{array}$ & $\begin{array}{l}\text { Issue rate } \\
\% \text { of total } \\
\text { pledges }\end{array}$ & $\begin{array}{l}\text { Selection rate } \\
\% \text { of total contracts }\end{array}$ & $\begin{array}{l}\text { Total } \\
\text { pledged } \$\end{array}$ & $\begin{array}{l}\text { Average } \\
\text { pledge } \$\end{array}$ \\
\hline Keep Families Together & Oct & 3 & 2 & 15 & 268.00 & 3.23 \\
$\begin{array}{l}\text { Fight Climate Change } \\
\text { Cyclone Protector }\end{array}$ & Nov & 3 & 5 & 22 & 392.00 & 3.19 \\
$\begin{array}{l}\text { Shine a Light } \\
\text { on Refugees }\end{array}$ & Nov & 3 + custom & 12 & 15 & 296.10 & 3.48 \\
Earthquake Insurance & Oct & 3 + custom & 13 & 23 & 388.60 & 3.04 \\
\hline
\end{tabular}

However, participants also said they would prefer to create fewer new contracts and that users should be able to repeat a contract, for instance, by pushing a button once every two weeks. Aware that durations affected issuing donations, participants often assumed that future implementations would offer longer contracts; one, who felt a "little demoralised" by eight expired contracts, said "if only they had been able to stay up a little longer, I'm confident that these conditions will have been met". While some participants reported that they would "set and forget" and "passively receive status updates" until their donation limit was reached, others checked often for instance, one explained, "as I knew it was only active 14 days, I was checking to see if the money was gone". Our aim to encourage varied interactions also affected the amounts involved. Several participants said they had too little money, for instance, "ten dollars and they want to split this in how many times? So, what are you giving, like 30 pennies or something!" Participants increasingly set up contracts for the entire amount:

Whenever I knew there was money remaining, I would set a contract for all of it and then check back to see every now and then (maybe once a week or fortnight) to see if the contract was making progress. - Interview P111 Participants said that, over the trial, they increasingly selected contracts that knew would result in a donation not those that "timed out more often". The platform analytics shows they made larger pledges to causes that issued donations more often (Table 6) and selected options for conditions that were more likely to be met, for instance, Sound the alarm required a cyclone to form but not to make landfall unlike Pacific Defender or Cyclone relief (Table 7). Determining relationships between contract selection and frequency of meeting conditions from the analytics is complicated by the many temporal variables in the trial, including varied contract durations, when users downloaded the app or ceased interacting with it. Nonetheless, participants often selected the cause that triggered most when given extra vouchers and when notified the trial would soon end (Figure 3$)$. The correlation between contract selection and rate of issuing donations was not, however, a proportional ratio (coefficient $=0.76$ ). For instance, participants selected Earthquake Insurance only slightly more than Shine a Light on Refugees even though it issued donations seven times more often ( $\underline{\text { Table 6 }}$ ). Thus, while participants sought to optimise time in the trial, aligned with ideas about productivity and speed, participants interactions were not only about donating efficiently, as we describe next.

Table 7: frequencies of setting up and customising each contract

\begin{tabular}{|c|c|c|c|c|}
\hline Cause & $\begin{array}{l}\text { Total } \\
\text { pledges }\end{array}$ & $\begin{array}{l}\text { Smart Plan and } \\
\text { Contract Builder }\end{array}$ & $\begin{array}{l}\text { Most likely contract of each cause to } \\
\text { trigger (see: Tables } 1 \text { to } \underline{5} \text { ) }\end{array}$ & $\begin{array}{l}\text { Selection rate } \\
\text { relative to } \\
\text { cause } \%\end{array}$ \\
\hline \multirow{3}{*}{$\begin{array}{l}\text { Keep Families } \\
\text { Together }\end{array}$} & \multirow{3}{*}{83} & Celebrating milestones & & 19.3 \\
\hline & & Hit the target & & 21.7 \\
\hline & & Every voice counts & Only 100 new signatures needed & 59.0 \\
\hline \multirow{4}{*}{ Cyclone Protector } & \multirow{4}{*}{85} & Cyclone relief & & 10.6 \\
\hline & & Custom contract & & 17.6 \\
\hline & & Pacific Defender & & 21.2 \\
\hline & & Sound the alarm & A cyclone only needs to form & 50.6 \\
\hline \multirow{3}{*}{$\begin{array}{l}\text { Fight Climate } \\
\text { Change }\end{array}$} & \multirow{3}{*}{123} & Too hot to handle & \multirow{3}{*}{ Similar likelihood of triggering } & 27.6 \\
\hline & & Melting in Melbourne & & 35.8 \\
\hline & & November heatwave & & 36.6 \\
\hline \multirow{4}{*}{$\begin{array}{l}\text { Shine a Light } \\
\text { on Refugees }\end{array}$} & \multirow{4}{*}{128} & Custom contract & & 14.1 \\
\hline & & Safe harbor & & 22.7 \\
\hline & & Mention Medevac & & 29.9 \\
\hline & & Hear the debate & $\begin{array}{l}\text { Any account tweets about "refugees or } \\
\text { migration }\end{array}$ & 34.4 \\
\hline
\end{tabular}




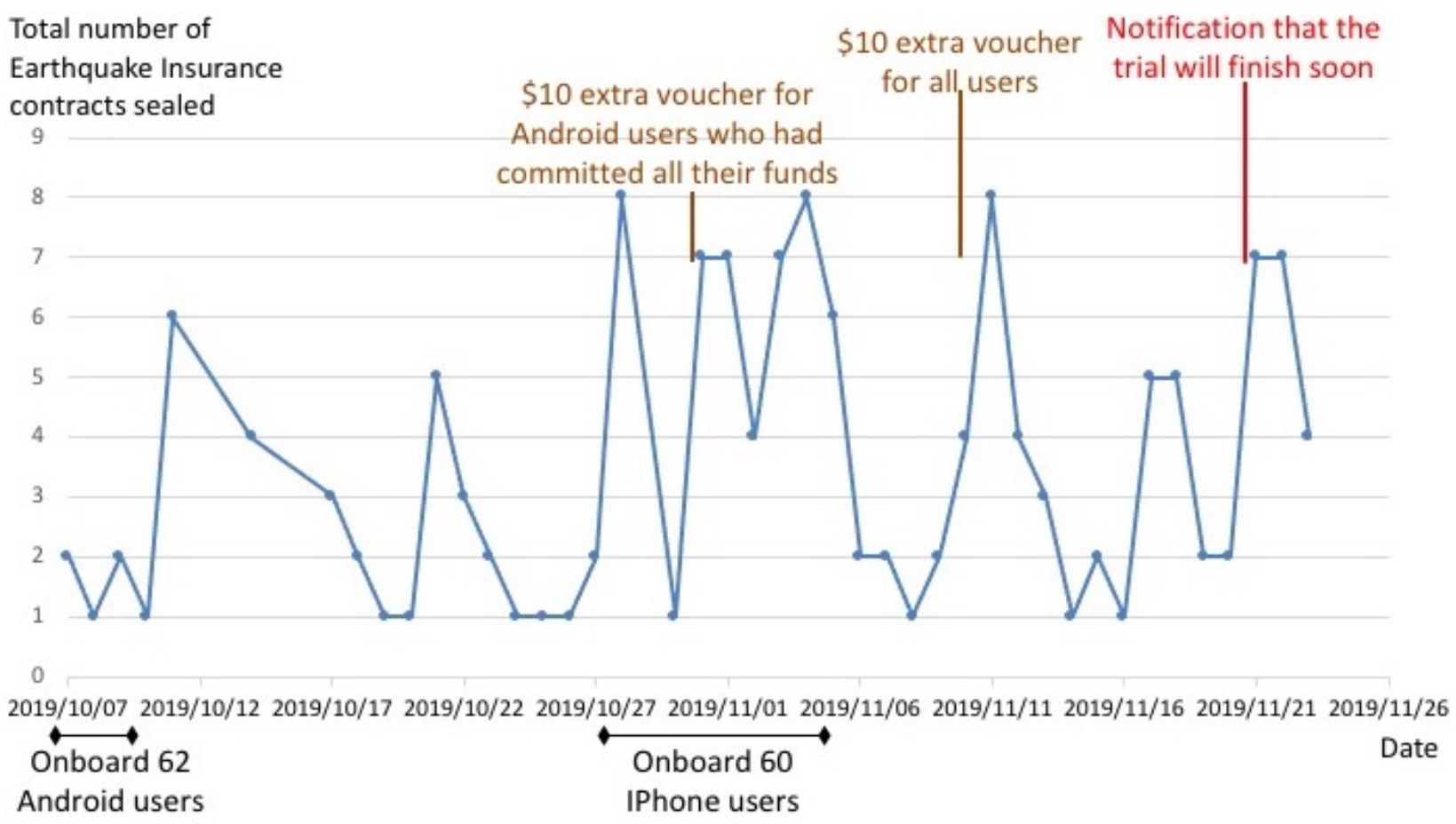

Figure 3: Rate of successfully setting up Earthquake Insurance contracts across the trial. Time is plotted in UCT, not Australian local time.

\subsection{Temporalities in Engagement}

Participants wrote on the questionnaire that they engaged with the app once or twice (18/49) or a few (15/49) times every week. The analytics shows that they often logged on without interaction or just to check the status of contracts and had on average 11 longer interactive sessions across the trial. The three most interactive users had 71,46 and 41 longer sessions. Most participants in interviews said they spent time at the start of the trial reading information, exploring the app's functionality, determining how contracts work and setting up some, often "fascinated by what the different triggers [are]". The analytics suggest that the average time participants spent in creating pledges was longer for their first few sessions (approximately 8 minutes) than the last few (just over 3 minutes), and some respondents to the questionnaire reported using the app "several times a day to start then less frequent". Respondents also replied that their interest in the app varied over time (21/51), or they were interested and engaged for most of the trial (14/51). In interviews some participants said they only used it when they had unpledged funds, while others said they couldn't find their login details or became busier. In this section we suggest that participants' engagement was shaped by some similar temporal registers in their lives but they had varied perspectives on how the app's temporal qualities synchronise their experiences of giving with the experiences of other people.

\subsubsection{Personal and Collective Rhythms.}

Participants reported, on the questionnaire, using the app nearly twice as much on weekdays compared to weekends. Analytics also showed that sessions were, on average, shorter by 20 seconds on weekends and there was most use on Mondays, especially for sessions with actual donations, however, few respondents to the questionnaire wrote that they allocated a specific day or time to use the app. Rather they usually used the app while having a break in their routine (22/51), such as "while my young child was sleeping!" or doing something else, such as watching TV (9/51) and commuting to (10/51) or from (15/51) work. Interview participants referred to infrastructural rhythms that might shape longer term use. Several spoke of annual events when they might review whether the cause they currently donate to "is still effective" and plan "how much they would like to donate over a certain time period"; for instance, one said: 
... I'm going to sit down every Christmas with the kids - or whoever it might be - and say, 'right here's our humanitarian contracts for the year' and then when you're mad busy with life and work and everything and a disaster happens you go 'oh, I've already done it, excellent - I know that I've already done that, and it's taken care of and I don't need to scramble around to remember to do something' - Interview P123

Two spoke of Christmas as a register for planning donations and, indeed, sociable or collective rhythms featured in some participants' engagement with the app. One who does not usually discuss her charitable donations with others was excited to tell people about the app and had not only discussed her contracts with her husband but, when she got an update had explained the app to people sitting near her on the bus. Another participant explained "it's collective in nature and it's not coming from a big centralised bank or insurance company", and yet another reflected on the way crowdfunding induces people to give simultaneously. He linked use of the platform to a sense of "community":

It sort of made me feel a little bit like I was part of a cohesive group of people doing something. I suppose an interesting part of that would be to know how many others might be on board with you at the same time. How many others have just given a dollar or whatever it is to this initiative? - Interview P112

A further participant explained he tweeted to encourage signatures on the petition that generated the data for a Keep Families Together contract he had created. While the potential for collectivism appealed to some participants, others spoke of "too much noise [when] a lot of people try to push the same barrow at the same time" and that they did not want their donations to depend on strangers, temporal patterns that emerge within groups or, as one said, "whatever stupid thing can become a trend in Twitter". Indeed, some participants had more individualistic responses to infrastructural rhythms when they related annual fiscal events to giving, such as preparing accounts and receiving refunds for income tax. Some suggested that Oxfam Australia should send special emails or notifications when contracts were about to expire at the end of the financial year, such as "do you want to just donate the rest to us anyway and get the tax deduction?".

Participants' interactions in the trial, and their speculated long-term engagement with the app, were shaped by generally similar everyday rhythms and infrastructural registers. However, they had different perspectives on situating contracts in "collective time" [99] or communal temporalities. While a phone-based app afforded individual convenience and interacting in personal "plastic time" [37], the automation and public data involved can enable donors to create new temporal patterns of giving with others. Users' synchronised experience of donating and receiving a notification of an event, because their contracts use the same data, contributes a form of sociability to the emotional engagement in causes. Yet, as described next the tempo of the notifications also needs to reconcile with people's individual lives.

\subsubsection{Balancing Donation Events and Everyday Life.}

Participants tried to judge how often donations would be triggered and reconcile the resulting tempo with their lives. Notifications were the primary way they became aware an event had occurred, such as an earthquake or tweet, and that a donation had been made. While a few participants said they chose when to engage with the app, most re-engaged when they received notifications and emails about changes to the app or additional funds. They varied in how long after receiving a notification they logged on, although one participant wrote in the questionnaire that they used the app as soon as possible. For some the volume of notifications was appropriate compared with other apps they disabled, and one said: "if people are engaged enough to give to a cause though I think there's an element of goodwill there regardless". Two participants said notifications were insufficient; one realised they were turned off only after checking the app to discover with surprise that all their money was gone, and the other experienced notifications as "random". Several said they didn't want to "be bombarded with it all the time" and ordinarily get frustrated the many notifications that they "flick away".

"It's exciting the first time to hear about an earthquake that you didn't hear about in the news", a participant said, "but after the $200^{\text {th }}$ one l'm not sure!". Participants sought a balance between the frequencies of notifications and emotional responses to realworld events of varying predictability and importance, or as one said between it, "going off all the time and now it's just annoying" [... and] going off often enough to keep you "oh, well it's gone off again, that's good!'”. Many tried to judge how event thresholds related to the frequency of notifications. Some said they needed more guidance, such as a warning when signing a contract at times when there were an unusual number of events. Others suggested that users should be asked if they wanted to limit notifications and decide their frequency and proposed various ways of setting notifications to a certain frequency or above a certain sized event or amount donated. Participants differed widely in how often they envisaged they would engage with the app over longer periods, from as often as "four or five times a week" to annually. One projected that he would interact with the app monthly "just auditing what had happened in a big block of time". Several said they would prefer wrap-ups, every-few-days or once-a-week, linked to a dashboard that they could check periodically. Others suggested a yearly update with "a good news story about what's happened".

Perspectives on the relationship between events, donating and notifications reflect diverse perceptions of temporality via the app. Participants related notification frequency to the size of donation, significance of event, expectations of engagement, constant interactivity, distraction and so on. This suggests "pluritemporality" [66] is fundamental to users' experiences of automation, even when their experiences are synchronised through contracts that use the same data.

\subsection{Felt-Experiences in the Trajectories of Contracts}

A respondent to the questionnaire wrote that an "emotional pull" is integral to decisions to donate but entering into a contract weeks or months beforehand is "more of a cognitive experience". Yet complex felt-experiences emerged as participants set up and followed the progress of contracts, as this section describes. 


\subsubsection{Anticipation in Setting Up Contracts.}

Some participants wondered whether premeditating events and predicting risk might detract from the emotions that prompt donating in an emergency. They mentioned, however, that a phone-based app avoided social pressure, negative emotions of ad-hoc fundraising requests and "being cranky for getting asked again!", as a participant said about the discomfort in replying, "I can't at the moment because I've already donated to this and I can't right now". Further participants often spoke of feeling "emotionally committed" to the money being used. In fact, the combination of their commitment and uncertainty about whether a donation would be triggered before the contract expired contributed to participants' engagement. While some sought information before setting up contracts, because they were unsure about the size and frequency of events and the places that would be most affected, many learnt how contracts performed by setting up different options and then experiencing the resulting presence or absence of notifications across the contract's duration. Some spoke of controlling the speed of releasing funds by setting thresholds, donation amounts and one-off rather than instalments. Their efforts to tune contracts were not merely about playfulness, however, and they had different experiences of contracts that more often released funds, such as Earthquake Insurance.

One participant had laughed when a friend said, "it's like betting!", because "too many days went by" without her conditions being met; however, she also described that after her disappointment when a contract expired an urge to "find my next offer" and a "dopamine hit". Yet, another, who had hesitated to compare setting up contracts to betting, in case we or Oxfam Australia became concerned that we were "getting people hooked on gambling for doing charitable donations!", found the complex feelings curious. He explained,

... so that wasn't a reflection that I had initially but only l'd sort of put in a bunch of different contracts. I was like 'oh wow, I've actually made a series of bets and I know how much I've committed, like 'if this happens commit up to $\$ 20$ or $\$ 10$ or whatever' but it hadn't happened yet. And so you enter this strange space of going 'oh, well if that happens it's going to cost me money' and then you go 'well, that's the point!' So I had to keep going 'but that's what I want to happen - I do want to donate money!' And so, I think there's this strange feeling of "I've put money down but I haven't handed it over yet". - Interview P123

Contrary to concerns that entering into a contract distracts from emotions that induce giving, our findings suggest felt-

experiences engaged participants in anticipating events. Setting up and tuning contracts was pleasurable or compelling for some while delayed payment and uncertainty about whether a donation would actually occur combined with participants' sense of commitment or reflective reasoning about their pledge.

\subsubsection{The Complications of Resolved and Expired Contracts.}

Participants distinguished between felt-experiences in planning a contract and when an event triggered a donation. Some contrasted the one-off thoughts involved in setting up contracts with a repeated readiness to actually donate; for instance, one said, "once you decided this is a cause for you, you are ready to give funds every time this happens". Some referred to shifts from financial to emotional investment, for instance, a participant explained, as he reviewed the app for the first time since the trial:

On 3rd November an earthquake of magnitude 5.1 struck New Zealand, this issued a donation of $\$ 2.50$ to the International Crisis Fund. And so my reaction - it was actually the first contract to validate which is obviously exciting in its own way and so I actually had mixed feelings because I initially jumped in, seeing the notification and thought "this is wonderful, I've donated some money" and then quickly, I guess, recoiled from that reaction because here I am celebrating the fact that a 5.1 magnitude earthquake had hit New Zealand! And so I sat with those thoughts for a moment and actually wondered how that might manifest at a larger scale.... [ ] not only a pleasure that I felt I had done something, and the contract had worked, and it validated my... I guess my contract design and my involvement in the trial. But it also made me aware of something, that I was now financially... I was already financially invested in it and now I became emotionally invested in it, as soon as the event actually took place. - Interview P284

The emotions when contract conditions were met, or not, are complicated and dynamic. Participants said that although they "should feel happy that nothing bad is happening!", instead they felt disappointment when the conditions of a contract, to which they had committed, were not satisfied, followed by excitement or frustration in needing to set up a new contract. Conversely, initial excitement, pleasure or satisfaction felt when the contracts they set up led to donations was offset by guilt. In the questionnaire a participant wrote that they disliked that the earthquake contract was actually met within 20 minutes of setting it as they "didn't realise how often the plates moved". Another said in an interview that guilt when receiving updates was unwelcome, even if charities leverage these feelings to induce donations:

It's this jolting reminder of I'm just living my privileged life here in Australia and people are suffering and maybe I should be doing more....And maybe that's a feeling that is useful for Oxfam Australia to induce a little bit but... it doesn't feel like a positive experience, it's not something l'd actively try and invite more into my life at an instinctive, emotional level. - Interview P112

The dynamics and ambiguities of felt-experiences in the time between contracts are set up, triggered or expired ${ }_{2}$ show that entering into a contract is not only a cognitive experience. Participants' commitment in signing a contract became a deeper emotional investment when an event triggered a donationn. They shifted between feeling eexcited, pleased or satisfied, and disappointed, guilty or frustrated when they contemplated the outcome of their contract design and the meaning of events happening or not. 


\subsubsection{Ongoingness between Set and (Not) Forget.}

Participants tended to think of the money as "gone" once they signed a contract and not that they saved money when pledged funds were returned. Thus, several suggested that funds should roll-over, into a related or donor-nominated cause, if conditions were unmet. They also said that although the money was real and was going to Oxfam, as one explained, "it wasn't my money, so I think that kind of made me treat things differently". Participants suggested that in routine use they would have less need to "feel that urge of donating", as one said, "I've got all my bets, or I've got all my contracts covered and I know how that will pan out". Others spoke of the convenience of "set and forget" so they would not have to dedicate time to sign another contract. Yet, forget related to not needing to do something within a certain time rather than not at all. An Oxfam Australia employee who used to run a mobile app team in a major bank said, "it wasn't 'set and forget' like other methods, it was one that I could actually [] check back in on".

Indeed, participants spoke of a continuous "bond" or "constant reminder". One distinguished Smart Contracts from a traditional donation to an emergency appeal, that "goes into a bucket and you don't know where it goes", and proposed contracts create ties into cause-and-effect relationships:

.. I can actually (read) the cause that it was headed towards, I can understand the conditions that it was going to be applied by and I could set a funding level that would then be associated directly to real-time events. So for me it was around that engagement and that cause-and-effect piece where a situation happens, I have something sitting in a bank of money there, that can be drawn down on, as needed, for that cause that l've got that tie into. - Interview P165

Feeling the need to set up contracts within the limited time of our trial was often inconvenient. However, the thoughts involved in setting up a contract that links funds to specific events creates an emotional commitment. The dynamics and intensity of contradictory felt-experiences might subside with long-term use of the app, yet it appears that the bond that emerges in commitments to real-world events might be sustained.

\subsection{Experiencing Right Times}

While participants had different experiences of temporality while engaging with the app many similar emotional and moral qualities emerged as contracts unfolded. Often, they imagined that their engagement would vary along the trajectories of contracts of longer durations, as one explained:

... there would be moments where I would become less engaged, especially if, just the real-life way I guess programmes and campaigns work, there are periods where there may be less things happening and then suddenly there's a lot going on in a very short space of time. So my engagement would probably reflect that, if it was tied to specific projects. - Interview P80

To conclude our findings, we suggest the app created opportunities for participants to experience right times to donate by supporting their sense of connection with phenomena and a charity's response in the real-world.

\subsubsection{Immediacy and Agency in Emergency Responses.}

Participants related the affordance of "instant reactivity" and donating to current situations to emotional or active involvement. While many spoke of the way an emergency triggers a donation immediately without requiring them to access their "bank accounts and spend that whole five minutes actioning a donation", this was not about convenience but about fighting, helping and supporting exactly when needed. A participant explained:

Whereas a generic once-a-year donation or once-a-month or whatever, at least you don't get-, you don't have that kind of sense of "oh, I'm doing my bit when I see something on the news" you kind of think "oh this is nice, I'm donating to Oxfam, they do some work, they send me an email..." but yeah, I think the app and the triggers and things are a lot more engaging and people will feel like they are kind of-, I guess actively participating as opposed to sort of passively giving something because they feel they should. - Interview P125

Participants referred to a sense of assisting responses. In interviews they commented on feeling personally involved because they set up a contract that meant their money was "already there" as events "far away" unfolded. They related this to helping the people affected have what is needed to "keep them alive right now". Two participants referred to the urgency that characterises the market in news in Australia and charity appeals. One observed that appeals attract "the vast majority of [] donations from the public in a very short amount of time" and another referred to how interest in emergency relief, immediately after disasters, did not sustain: "better throw a bit of money at that problem now, and move on..."

Participants said that contracts that could enable rapid emergency responses appeared important, pragmatic and sensible. They wrote in questionnaires, for instance, that they "liked the immediacy of the organisation being able to access funds" in response "to an urgent situation" and interviews spoke of creating "a pool of funds". Two participants, with work experience in disaster response related the escrow to charities' strategies for deploying funding reserves. One spoke of the use of 'predictive financing' to aggregate data about the likelihood of weather events, such as typhoons and droughts, to ensure funds are available for 'early action'. Others suggested that funds in the escrow circumvented delays that arise as charities coordinate fundraising and involve people in campaigns and by providing some confidence around how much funds will be donated would enable Oxfam Australia to respond more quickly. Participants with experience of emergency responses spoke of the benefits of a "guaranteed assef" or a "firmly bound contract" to deciding "in the first 72 hours, what you do in the first week, two weeks, of a response". Reference to the timeliness of a donation often related to quantified clock-time. For instance, a participant who lives in the Middle East related a donor's response to the efficacy of emergency action on the ground: 
... I knew about it when it happened, I didn't wait to eight o'clock, at eight o'clock that mean that six or seven hours [] disappear and that means the 72 hours to find those people, also they disappear. Even if I want to donate, let's say $\$ 100$ and they know about it in eight o'clock in the afternoon, and I said "OK, let me take my credit card and then to make the donation and blah blah blah - let me do it in the morning" but going in the morning that means we lost 20 hours. - Interview P120

Participants' interest in the most "reactive" contracts, their senses of immediacy and linking response logistics to clock-time corresponds with cultural emphases on constant change and speed, both reflected in and reproduced by the focus of news and charity appeals. In fact the actual logistics of real-world emergency response may mean Smart Donations cannot actually accelerate disaster management. However, the timeliness of donations could help Oxfam Australia base decisions on better estimates of the funding available.

\subsubsection{Involved in Long Term Responses.}

The issue rates of Earthquake Insurance and Cyclone Protector were significantly higher than the Keep Families Together and Fight Climate Change contracts, which contributed to perceptions that the app best suits donating to discrete crisis events. However, some participants differentiated between slow- and rapid- onset crises and suggested Smart Donations might sustain donors' involvement across longer durations by integrating other temporal qualities. Referring to his experience in charity campaigns a participant explained that fundraising has a "very, very big peak at the beginning" and "dribs and drabs later". He suggested linking donations to "objective measures" of changing conditions until a situation is under control:

... if you were to set up a contract with people and say "hey, look, the drought's kicking off - it's starting to look bad". You agree with people that once a month you'll take another donation - another $\$ 20$ or another $\$ 50$ or whatever - if the rating is still that high. - Interview P123

Explicit links between contract conditions and the impacts of donations on ongoing situations were unclear in the trial and some participants wondered about the timeframe for use of their donations in projects, such as climate change. Indeed, climate change and refugee crises, are long-term concerns that, as one participant explained "are not going to be solved. They're not here-today-gone-tomorrow sort of exercises". Some participants said that an ongoing awareness helped them follow a campaign and valued being kept up to date with national politics and campaigns with "a slower burn", such as Shine a Light on Refugees. One said that she had not heard anything on the news on the few days when she was notified of tweets that triggered her donation. Another explained that while politicians did not tweet his selected keywords before his contract expired, had it been a few weeks later "it would have gone off every five minutes". Participants observed that linking real-time events to ongoing donations can help donors feel involved in long-term change and prompt them to interact more regularly, as a woman who works in business software enthused:

... I donate on a monthly basis to a children's charity that does community development and stuff like that. But it's very much a back-of-mind thing because it gets taken out of my account on a monthly basis and I know it's there, but I don't get-, you know, like this app, I don't get kind of daily reminders of what's going on in the world. Interview P278

Another participant proposed that interim conditions, steps or checkpoints for contracts would enhance the experience of regular donors who do not receive feedback and how a dashboard would enable him to track the progress of his contracts. He sought to "scale up or scale down funding", according to unfolding events and suggested he would donate "a small seed amount" and then more if a threshold was reached or his interested increased. Indeed, several participants spoke of the potential for the app to engage users in, as one put it, "milestones", such as " "we've hit outcome 1 and so now we're working towards this". Another participant spoke of "smooth insurance delivery" based on parameters in predicted impacts, explaining:

... these conditions are likely to lead to crop loss or lead to some amount of financial difficulty so if we can preempt that we can start to, I guess, even out the peaks and the troughs of the cash flow or the production of a farmer in this case. - Interview P284

Participants valued updates in slowly unfolding or ongoing situations. Becoming aware of the temporalities of events can help donors to feel involved in long-term change, prompt them to interact and adapt their donations. As our final theme suggests it also made participants more conscious of living in a dynamic world.

\subsubsection{Connections to Stories in a Dynamic world.}

A participant remarked that Earthquake Insurance notifications reminded him that "we all live on land that is literally floating on a magma of semi-solid stuff down below! And even the earth beneath our feet!", and another wrote that he liked that "there was a change in earth movements and occurred so quickly". Indeed, several participants were intrigued by the frequency of minor earthquakes and a few spoke about how realising the frequency of events can help educate people about the scale of a crisis, such as triggering "whenever a refugee boat is spotted on the Mediterranean". Many participants said they liked that they learnt about events in "real time" that they would not otherwise have encountered and how notifications, as one said, "created a new narrative stream for me to explore, that I wouldn't have otherwise explored".

Notifications went further than newsfeeds by offering information that was tuned to participant's interests or prompted thinking about the world. Some spoke of being able to control their own news cycle, and how this can provoke people "to create their own awareness". One said, with a sigh, that "personal things", like asylum seekers and separating children from parents, are "not reported very often and it should be". Conversely, participants became aware of the absence of events wondering "why haven't the conditions been met on this?", after contracts expired multiple times. Absence can reveal issues that need attention, explained a participant as she reviewed her contracts based on a politician's tweets: 
... I really liked having that kind of notification of "Kristina Keneally is tweeting something about medevac or \#LetThemStay" or something like that. Because it's something I'm interested in and I was kind of surprised actually that they didn't mention it more often, during that time, because there was a family who had been in Australia for some time but was being 'sent back' in very strange circumstances. - Interview P278

Some participants suggested notifications and visualisations that tracked expenditures and allocations of donations in real-time would reassure and motivate donors. Knowing the date of spending or distribution had value, such as "they've purchased blankets on this day, they've handed out blankets on another [day]", one said. Another suggested:

So "your donation was used on this particular intervention" or more likely "back in October 2019 you gave $\$ 2.50$, today January 3rd, it was used in an intervention in Fuji as part of a larger donation to a family in a food programme, here is the link to the programme". - Interview P284

Other comments indicate information about the timing of allocations actually related to connecting to stories about beneficiaries. A participant reflected that she'd "end up Googling the village" where her donation had helped - "not to find the people!", she laughed, "to get a better understanding of where is this village where this earthquake has just happened". For many participants their sense of connection resonated most with contracts that were "an event in the world, as opposed to a tweet". Various comments indicated the potential for intimate connections; participants sought to avoid "personal, confronting topics" in contracts, such as not receiving notifications every time a "woman has been raped in this context", and how living closer to the Pacific made the path of a cyclone more interesting.

An increased awareness of the temporalities of events contributed to participants noticing connections between themselves, real-world ecological and political phenomena and a charity's response, and also when matters were widely ignored. This awareness promoted them to seek more understanding of issues and particulars. Noticing connections and realising a personal involvement in the dynamics of the world, even without knowing exactly what the funds are spent on or when they were spent, suggests that Smart Donations can open up opportunities for a sense of the right time to donate.

\section{Discussion}

Our findings suggest that conditional and data-driven automation can open up opportunities for a sense of the right time to donate because people experience the juxtaposition of different temporal registers. We now reflect on how this juxtaposition fostered senses of connection and agency in using Smart Donations, and on insights about the foundational role of temporality in users' experiences that sensitise us to some undesired effects. Then we discuss how algorithms that financialise data about events in the world are usually optimized for certain efficiencies and detached from the multiple temporalities of the world and infer what this might mean for manipulating blocktime. This brings us to advocating for designers to consider multiple temporalities and the ways that automation may be used to enrich users experiences of right times in financial transactions.

\subsection{Felt-Experiences When Automation Juxtaposes Temporalities}

When a blockchain-based financial escrow enforces the timing of donations people can experience the juxtaposition of different temporal registers. Usually when we encounter political and environmental events in online news, social media or information in a charity appeal, we treat them as if they are happening in the same temporal registers as ourselves. The events and our encounter with information about them on our newsfeed are asynchronous but, affected by the "condition of immediacy" [48], we experience them as if they occur with the tempo of our lives. Users do not control when smart donation happen, however, thus when they are notified about the causative events various temporalities juxtaposes; those in their personal routines, the phenomena, such as earthquakes, weather or public political discourse, and in the charity's work to respond. Participants set up contracts in gaps or plastic time, such as during a commute or while watching TV. This temporal control avoids the discomfort they might feel when asked to give by, or say no to, a fundraiser [4] and did not seem to inhibit a warm glow since their funds are held in escrow. However, the inflexibility enforced by the escrow prompts or intensifies felt-experiences and emotional and moral ambiguities when donations do or do not result. Users felt gratified and then guilty by the success of their contract design when donations were made. They felt disappointed then remorseful, and then sometimes relieved, when inactive contracts expired, and frustrated or excited to set up another. Users can select contracts that are more likely to meet the conditions within a certain period and manipulate constraints, such as thresholds and whether or not to release funds gradually; yet, ultimately, the bursts of contradictory felt-experiences elicited align with the occurrence or absence of events. The tempo of notifications affects users' emotional investment and increase awareness of phenomena around the world, which prompted participants in the trial to feel part of a dynamic world. Thus, somewhat paradoxically, automated conditionality prompted emotional connections between digital and real-world events.

Participants also felt agency because the timing of notifications differed from mainstream news cycles and emphases. Somewhat alike Facebook users who read posts with a "nowness" [34], participants contextualised notifications in a story-like experience, or a "narrative stream", and imagined what happens next in an emergency response. Their feelings of satisfaction in having done something by setting up a contract extended across the duration of repeated donations, based on low threshold conditions, an ongoingness resonant of the connections that friends maintain through WhatsApp [64]. The logistics of deploying rescue missions to, say, the Himalayas after an earthquake, cannot happen with the immediacy of digital money transfer; however, the combination of instant awareness of events and release of funds contributes to participants' sense of involvement in emergency responses. 
Understanding the foundational role of temporality in users' experiences can inform designs to counter some of the unintended effects of Smart Donations on donor experiences and charitable acts. Insights about the emotional dynamics around contracts leads us to anticipate that some data and contract lengths will promote addictive, compulsive or attention-demanding use. Indeed, within the duration of the trial, and when not donating their own money, some participants compared setting up contracts with gambling. Using social media data to drive contracts can make the entanglement of finances, politics and online public opinion explicit, but also produces externalities. New temporal patterns can emerge when different people's contracts are driven by the same data. While synchronised experiences of donating can contribute to sociability, Twitter data can also entangle these patterns in polarization [54]. Insights about the nuances of temporality and social relations in users' experiences, such as setting up contracts at family gatherings and showing notifications to fellow passengers on the bus, may help inform designing to support more beneficial "commoning" effects (e.g. [8]).

\subsection{Enriching Opportunities for Right Time in Philanthropic Donations: Transparency and Awareness}

Users' sense of the right times to donate emerges as diverse temporal registers are juxtaposed. This concept of right time expands prior critiques of automation for "flattening" and failing to engage with the nuances of daily rhythms [75]. Bucher describes the "right-time" fabricated by algorithms by aggregating data on many people's interactions with information and, undoubtably, this will flatten personal moments into a "common personalized time regime" [12]. Yet, when users themselves program conditions using data about diverse phenomena, right time is not purely "the specific inner temporality of algorithmic media" [12]. Right time for Smart Donations arises in the relationship between algorithms, the conditions a user sets and the external phenomenon. The "right-time" fabricated by algorithms, Bucher explains, is neither "an objective phenomenon external to human activity nor as a subjective phenomenon bound to social norms and individual experience" [12]. Participants experienced the timing of data-driven donations, however, both objectively and subjectively. They constructed data about earthquakes and cyclones as more objective than tweets and petitions, and proposed that "objective" times for tracking ongoing conditions or spending funds was more compelling. Simultaneously, their references to objective measures were entwined with subjective connections to potential beneficiaries.

Right times to donate are, of course, diverse. For some, Smart Donations potentially offers a convenient way to craft donations at certain times of year that would be appropriately distributed in the background of everyday life. Such preferences align with prevailing paradigms for data and automation in digital financial services that infer efficient, frictionless transactions, framed by beliefs in saving time and a discourse of speed [95]. Other reflections, however, challenge this paradigm. An awareness of phenomena that usually go unnoticed enriched the experiences of giving for participants who described moments when Smart Donations alerted them to issues and dynamics they cared about and fostered senses of agency in responding to urgent needs and ongoing commitments to persisting circumstances. Such experiences resonate with studies that show payments can be a means of communication [2] and self-expression [17], or even a form of social media [85].

The concept of right time we apply expands prior considerations of temporal and slow design and Situational When that encourage more flexible, inclusive engagements with time and experiences linked to social and organic rhythms (e.g. [24, 31, $\underline{60}, \underline{61}, \underline{62}, 75,89,99])$. Taylor et al derived "Situational When" to account for the temporal convergence of social relations in determining the "right time" for something to happen" when designing interfaces for Aboriginal people [89]. Participants' experiences of Smart Donations, however, show the potential for automation to increase awareness of ecological, geological, meteorological, political and financial relations with time. Juxtaposing temporal registers prompted consciousness about power relations, for instance, a politician's momentary tweet can drive funds into a campaign to free a refugee who has been detained for years. Some participants proposed that the platform can help beat the politics of time embedded in getting a rescue operation off the ground, indicating its potential to widen understanding of the roles of financial transactions in development in an interconnected world [5]. Certainly, a sensitivity to temporalities that promotes a sense of being part of the world prioritises very different values than those embedded in other algorithms that financialise data about natural disasters. For instance, like Smart Donations, stock market algorithms produce new externalities using earthquake warning data, however, geared to gain competitive advantage for investors they are a financialization that is alienated from environmental systems [29]. The speed of digital transactions has reconfigured the dynamics of relationships between capital and nature and detached people from environmental systems [29]. Just like automated on-demand services, that normalise the temporal marginalisation of workers [13], financial transactions are usually optimized for efficiencies that make profit. Blocktime is already a time schema that is separate from events and temporal registers in the world, affording opportunities to manipulate time by arbitrage [84]. Framing the malleability of blocktime as a "resource" [84] is likely to orient any manipulation of the temporal differential towards profit. Thus, we encourage designers of FinTech to consider multiple temporalities. Specifically, we advocate for reflecting on the many relational ways that streams of data, transactional rules, and automated scheduling and prediction of events may be used to enrich people's judgements about a right time to pay; to save, to invest or divest, to boycott or bequeath; or just to give.

\section{Conclusion}

Our 8-week trial of Smart Donations provides rich context to explore people's experiences of donating when automation preserves and enforces their financial intentions. We did not explicitly design contracts to produce certain temporal experiences, temporal qualities that emerge contributed to participants' experiences in donating. Participants became aware of the different temporalities of phenomena in the world and the work of charities in responding to these phenomena, and how their awareness 
of these can be shaped by factors such as news cycles and deployment timelines. We propose automation, perhaps inadvertently, revealed temporal seams, or detectable intersections as different temporal registers juxtaposed. An awareness of the seams between different temporalities alongside each other contributed to senses of the right times when releasing funds was most opportune. The concept of right time, it appears, is not about perfectly aligning registers amidst all this temporal diversity. Rather, it is about responding flexibly based on an awareness of different temporalities. Since experiences of right time emerge in awareness of different temporalities, some participants' right time is compatible with prevailing paradigms in digital financial services that hide seams to facilitate convenience. For others, however, regular awareness of the juxtaposition of temporalities contributed to senses of immediacy in humanitarian needs, of ongoing involvement in "slow burning" circumstances and of connection to issues they cared in a dynamic world. Our sensitivity to this right time, helped us recognise diverse experiences in using Smart Donations, which grounds our ongoing analysis of other aspects of the trial. Thus, we encourage those designing FinTech to consider how a sensitivity to right time might support temporal orientations beyond saving time.

\section{ACKNOWLEDGMENTS}

This work has been funded by the UK EPSRC project "Ox-Chain: Towards secure and trustworthy circular economies through distributed ledger technologies" (EP/N028198/1) and the UK EPSRC "PETRAS loT Research Hub - Cybersecurity of the Internet of Things" (EP/N023234/1). We thank all participants in the trial. and our project partners Oxfam Australia and Oxfam Great Britain. We also thank the anonymous $\mathrm{CHI}$ reviewers for their critique.

\section{REFERENCES}

1. Syed Ishtiaque Ahmed, Nicola J. Bidwell, Himanshu Zade, Srihari H. Muralidhar, Anupama Dhareshwar, Baneen Karachiwala, Cedrick N Tandong and Jacki O'Neill. 2016. In: Proceedings the 2016 Conference on Human Factors in Computing Systems (CHI'16) 5063-5075. https://repository.up.ac.za/bitstream/handle/2263/57385/Ahmed_PeerToPeer_2016.pdf?sequence=3

2. Amelia Ackerand and Dhiraj Murthy. 2018. Venmo: Understanding mobile payments as social media. In: Proceedings of the 9th International Conference on Social Media and Society, 5-12.

3. Alice, decentralised platform for the social finance sector. https://alice.si/

4. James Andreoni and Marta Serra-Garcia. 2016. Time-inconsistent charitable giving (No. w22824). National Bureau of Economic Research. https://EconPapers.repec.org/RePEc:nbr:nberwo:22824

5. Matt Baillie Smith. 2013. Public imaginaries of development and complex subjectivities: the challenge for development studies. Canadian Journal of Development Studies, 34(3): 400-415.

6. Jakob E Bardram 2000. Temporal Coordination - On Time and Coordination of Collaborative Activities at a Surgical Department. Journal of Computer Supported Cooperative Work () 9(2): 157-187.

7. René Bekkers and Pamala Wiepking. 2011. A literature review of empirical studies of philanthropy: Eight mechanisms that drive charitable giving. Nonprofit and Voluntary Sector Quarterly 40(5): 924-973.

8. Nicola J. Bidwell. 2020. Wireless in the Weather-world and Community Networks Made to Last. In: Proceedings of. the 2020 Biennial Participatory Design Conference.

9. Nicola J. Bidwell, Thomas Reitmaier, Carlos Rey-Moreno, Zukile Roro, Masbulele Jay Siya and Bongiwe Dlutu. 2013. Timely relations in rural Africa. In: Proceedings of 12th International Conference on Social Implications of Computers in Developing Countries. The International Federation for Information Processing (IFIP) WG 9.4: 92 -106.

10. Nicola J. Bidwell, Peta-Marie Standley, Tommy George and Vicus Steffensen. 2008. The Landscape's Apprentice: Lessons for PlaceCentred Design from Grounding Documentary. In: Proceedings of the 7th ACM Conference on Designing Interactive Systems, 88-98.

11. Chris Bopp, Ellie Harmon and Amy Voida. 2017. Disempowered by Data: Nonprofits, Social Enterprises and the Consequences of DataDriven Work. In: Proceedings of the 2017 Conference on Human Factors in Computing Systems (CHI'17) 3608-3619. DOI: https://doi.org/10.1145/3025453.302569

12. Tania Bucher. 2020. The right-time web: Theorizing the kairologic of algorithmic media. New Media \& Society 22(9) 1699-1714

13. Julie Yujie Chen and Ping Sun. 2020. Temporal arbitrage, fragmented rush and opportunistic behaviors: The labor politics of time in the platform economy. New Media \& Society, 22(9) 1561-1579.

14. Nazli Cila, Gabriele Ferri, Martijn de Waal, Inte Gloerich and Tara Karpinski. 2020. The Blockchain and the Commons: Dilemmas in the Design of Local Platforms. In: Proceedings of the 2020 Conference on Human Factors in Computing Systems (CHI'20) 1-14. DOI: https://doi.org/10.1145/3313831.3376660

15. Giulio Coppi and Larissa Fast. 2019 Blockchain and distributed ledger technologies in the humanitarian sector. HPG Commissioned Report. www.econstor.eu/handle/10419/193658

16. Disperse, platform for donors and aid organisations. https://disberse.com/

17. Chris Elsden, Tom Feltwell, Belén Barros Pena, Bettina Nissen, Inte Gloerich, Chris Speed and John Vines. 2020. Designing Futures of Money and FinTech. In Companion Publication of the 2020 ACM Designing Interactive Systems Conference (DIS'20 Companion), $429-432$. DOI: https://doi.org/10.1145/3393914.3395904 
18. Chris Elsden, Tom Feltwell, Shaun Lawson and John Vines. 2019. Recipes for Programmable Money. In: Proceedings of the 2019 Conference on Human Factors in Computing Systems (CHI'19) Paper 251, 1-13. DOI: https://doi.org/10.1145/3290605.3300481

19. Chris Elsden, Arthi Manohar, Jo Briggs, Mike Harding, Chris Speed and John Vines. 2018. Making Sense of Blockchain Applications: A Typology for $\mathrm{HCl}$. In: Proceedings of the 2018 Conference on Human Factors in Computing Systems (CHI'18) Paper 458, 1-14. DOI: https://doi.org/10.1145/3173574.3174032

20. Chris Elsden, Kate Symons, Raluca Bunduchi, Chris Speed and John Vines. 2019. Sorting Out Valuation in the Charity Shop: Designing for Data-Driven Innovation through Value Translation. In: Proceedings of the 2019 ACM Conference on Computer Supported Cooperative Work (CSCW'19), DOI: https://doi.org/10.1145/3359211

21. Chris Elsden, Ludwig Trotter, Mike Harding, Nigel Davies, Chris Speed and John Vines. 2019. Programmable Donations: Exploring Escrow-Based Conditional Giving. In: Proceedings of the 2019 Conference on Human Factors in Computing Systems (CHI'19) Paper 379, 113. DOI: https://doi.org/10.1145/3290605.3300609

22. Anton Fedosov, Agon Bexheti, Egor Ermolaev and Marc Langheinrich. 2018. Sharing physical objects using smart contracts. In: Proceedings of the 20th International Conference on Human-Computer Interaction with Mobile Devices and Services Adjunct (MobileHCl'18) 346-352. DOI: https://doi.org/10.1145/3236112.3236162

23. Jennifer Ferreira, Mark Perry and Sriram Subramanian. 2015. Spending Time with Money: From Shared Values to Social Connectivity. In: Proceedings of the 2015 ACM Conference on Computer Supported Cooperative Work \& Social Computing (CSCW'15) 1222-1234. DOI: https://doi.org/10.1145/2675133.2675230

24. Verena Fuchsberger, Martin Murer and Manfred Tscheligi. 2015. Time and Design: Seven Sensitivities. In: Proceedings of the Ninth International Conference on Tangible, Embedded and Embodied Interaction, 581-586.

25. Xianyi Gao, Gradeigh D. Clark and Janne Lindqvist. 2016. Of Two Minds, Multiple Addresses and One Ledger: Characterizing Opinions, Knowledge and Perceptions of Bitcoin Across Users and Non-Users. In: Proceedings of the 2016 Conference on Human Factors in Computing Systems (CHI'16) 1656-1668. DOI: https://doi.org/10.1145/2858036.2858049

26. Elizabeth M. Gerber, Michael Muller, Rick Wash, Lilly C. Irani, Amanda Williams and Elizabeth F. Churchill. 2014. Crowdfunding: an emerging field of research. In Extended Abstracts of the 2014 Conference on Human Factors in Computing Systems (CHI-EA '14) $1093-1098$. DOI: https://doi.org/10.1145/2559206.2579406

27. Ishita Ghosh and Jacki O'Neill. 2020. The Unbearable Modernity of Mobile Money. In: Proceedings of the 2020 ACM Conference on Computer Supported Cooperative Work and Social Computing (CSCW'20) 1-35.

28. Jeremy Goecks, Amy Voida, Stephen Voida and Elizabeth D. Mynatt. 2008. Charitable technologies: opportunities for collaborative computing in nonprofit fundraising. In: Proceedings of the 2008 ACM Conference on Computer Supported Cooperative Work (CSCW'08) 689698. DOI: https://doi.org/10.1145/1460563.1460669

29. Thomas Skou Grindsted 2020. Trading on earthquakes-Algorithmic financialization of tectonic events at global stock exchanges. Geoforum 108: 80-87

30. Jonathan D. Hall, Craig Palsson and Joseph Price. 2018. Is Uber a substitute or complement for public transit? Journal of Urban Economics 108: 36-50.

31. Lars Hallnäs and Johan Redström. 2001. Slow technology-designing for reflection. Personal and Ubiquitous Computing 5(3): 201-212.

32. Ellie Harmon, Chris Bopp and Amy Voida. 2017. The Design Fictions of Philanthropic IT: Stuck Between an Imperfect Present and an Impossible Future. In: Proceedings of the 2017 Conference on Human Factors in Computing Systems (CHI'17) 7015-7028. DOI: https://doi.org/10.1145/3025453.3025650

33. Ellie Harmon, Matthias Korn and Amy Voida. 2017. Supporting Everyday Philanthropy: Care Work In Situ and at Scale. In: Proceedings of the 2017 ACM Conference on Computer Supported Cooperative Work and Social Computing (CSCW'17) 1631-1645. DOI: https://doi.org/10.1145/2998181.2998330

34. Richard Harper, Eryn Whitworth and Ruth Page. 2012. Fixity: Identity, time and durée on Facebook. Selected Papers of Internet Research (2012).

35. Daniel Hellmann, Carleen Maitland and Andrea Tapia. 2016. Collaborative Analytics and Brokering in Digital Humanitarian Response. In: Proceedings of the 2016 ACM Conference on Computer-Supported Cooperative Work \& Social Computing (CSCW'16) 1284-1294. DOI: https://doi.org/10.1145/2818048.2820067

36. Tim Ingold. 2000. The Perception of the Environment: Essays on Livelihood, Dwelling and Skill. London \& New York: Routledge.

37. Lilly Irani, Robin Jeffries and Andrea Knight. 2010. Rhythms and plasticity: television temporality at home. Personal and Ubiquitous Computing 14(7): 621-632

38. Steven Jackson, David Ribes, Ayse Buyuktur and Geoffrey C. Bowker. 2011. Collaborative rhythm: temporal dissonance and alignment in collaborative scientific work. In: Proceedings of the 2011 ACM Conference on Computer Supported Cooperative work (CSCW) $245-254$.

39. Joseph Jofish Kaye, Mary McCuistion, Rebecca Gulotta and David A. Shamma. 2014. Money talks: tracking personal finances. In: Proceedings of the 2014 Conference on Human Factors in Computing System (CHI'14) 521-530. DOI: https://doi.org/10.1145/2556288.2556975 
40. Joseph Jofish Kaye, Janet Vertesi, Jennifer Ferreira, Barry Brown and Mark Perry. 2014. \#CHImoney: financial interactions, digital cash, capital exchange and mobile money. In: Extended Abstracts of the 2014 Conference on Human Factors in Computing System (CHI-EA'14) 111114. DOI: https://doi.org/10.1145/2559206.2559221

41. Joseph Kasera, Jacki O'Neill, Nicola J Bidwell. 2016. Sociality, Tempo \& Flow: Learning from Namibian Ride Sharing. In: Proceedings AfriCHI'16 African Conference for Human Computer Interaction. 978-1-4503-4830-0

42. Irni Eliana Khairuddin and Corina Sas. 2019. An Exploration of Bitcoin Mining Practices: Miners' Trust Challenges and Motivations. In: Proceedings of the 2019 Conference on Human Factors in Computing Systems (CHI'19), 1-13. DOI: https://doi.org/10.1145/3290605.3300859

43. Yong Ming Kow and Xianghua Ding. 2016. "Hey, I know what this is!": Cultural Affinities and Early Stage Appropriation of the Emerging Bitcoin Technology. In: Proceedings of the 19th International Conference on Supporting Group Work (GROUP'16). 213-221. DOI: https://doi.org/10.1145/2957276.2957279

44. Yong Ming Kow, Gui X., Cheng W. (2017) Special Digital Monies: The Design of Alipay and WeChat Wallet for Mobile Payment Practices in China. In: Proceedings of INTERACT 2017. Lecture Notes in Computer Science, vol 10516. Springer, Cham. https://doi.org/10.1007/978-3319-68059-0_9

45. Jonas Landgren. 2006. Making action visible in time-critical work. In: Proceedings of the 2006 Conference on Human Factors in Computing System (CHl'06) 201-210.

46. Gilly Leshed and Phoebe Sengers. 2011. I lie to myself that I have freedom in my own schedule: productivity tools and experiences of busyness. In: Proceedings of the 2011 Conference on Human Factors in Computing Systems (CHl'11), 905-914.

47. Makayla Lewis and Mark Perry. 2019. Follow the Money: Managing Personal Finance Digitally. In: Proceedings of the 2019 Conference on Human Factors in Computing Systems (CHI'19), 1-14. DOI: https://doi.org/10.1145/3290605.3300620

48. Siân Lindley. 2015. Making time. In: Proceedings of the 2015 ACM Conference on Computer Supported Cooperative work (CSCW'14) 56: 33-34

49. Caitlin Lustig and Bonni Nardi. (2015). Algorithmic authority: The case of Bitcoin. In Proceedings of 48th IEEE Hawaii International Conference on System Sciences 743-752.

50. Donald MacKenzie, Daniel Beunza, Yuval Millo \& Juan Pablo Pardo-Guerra (2012) Drilling Through The Allegheny Mountains. Journal of Cultural Economy, 5:3, 279-296, DOI: 10.1080/17530350.2012.674963

51. Reed Martin and Henry Holtzman. 2011. Kairoscope: managing time perception and scheduling through social event coordination. In: Proceedings of the 2011 Conference on Human Factors in Computing Systems (CHI'11) 1969-1978.

52. Nik Milanovic 2020. Self Driving Money. Forbes. www.forbes.com/sites/nikmilanovic/2020/07/21/self-driving-money-is-coming-forconsumer-fintech/\#2e9a562de106

53. Mareike Möhlmann and Ola Henfridsson. 2019. What people hate about being managed by algorithms, according to a study of Uber drivers. Harvard Business Review, 30

54. Matti Nelimarkka, Salla-Maaria Laaksonen and Bryan Semaan. 2018. Social media is polarized, social media is polarized: towards a new design agenda for mitigating polarization. In: Proceedings of the 2018 Designing Interactive Systems Conference, (DIS'18) 957-970

55. Magnus Nilsson and Morten Hertzum. 2005. Negotiated Rhythms of Mobile Work: Time, Place and Work Schedules. ACM In:. In: Proceedings of the 2005 International Conference on Supporting Group Work (GROUP'05). 148-157.

56. Bettina Nissen, Larissa Pschetz, Dave Murray-Rust, Hadi Mehrpouya, Shaune Oosthuizen and Chris Speed. 2018. GeoCoin: Supporting Ideation and Collaborative Design with Smart Contracts. In: Proceedings of the 2018 Conference on Human Factors in Computing Systems (CHI'18) 1-10. DOI: https://doi.org/10.1145/3173574.3173737

57. Bettina Nissen, Kate Symons, Ella Tallyn, Chris Speed, Deborah Maxwell and John Vines. 2017. New Value Transactions: Understanding and Designing for Distributed Autonomous Organisations. In Companion Publication of the 2017 ACM Designing Interactive Systems Conference (DIS'17 Companion). 352-355. DOI: https://doi.org/10.1145/3064857.3064862

58. Wendy Norris, Amy Voida, Leysia Palen and Stephen Voida. 2019. Is the Time Right Now?' Reconciling Sociotemporal Disorder in Distributed Team Work. In: Proceedings of the 2019 ACM Conference on Computer Supported Cooperative Work and Social Computing (CSCW'19): 1-29.

59. Rachel O'Dwyer. 2019 Cache society: transactional records, electronic money and cultural resistance, Journal of Cultural Economy, 12:2, 133-153, DOI: 10.1080/17530350.2018.1545243

60. William Odom, Ron Wakkary, Ishac Bertran, Matthew Harkness, Garnet Hertz, Jeroen Hol, Henry Lin, Bram Naus, Perry Tan, Pepijn Verburg and Emily Carr. 2018. Attending to Slowness and Temporality with Olly and Slow Game: A Design Inquiry into Supporting Longer-Term Relations with Everyday Computational Objects. In: Proceedings of the 2018 Conference on Human Factors in Computing System (CHI'18)

61. Will Odom, Banks, R., Durrant, A., Kirk, D., \& Pierce, J. 2012. Slow technology: critical reflection and future directions. In: Proceedings of the 2012 ACM Designing Interactive Systems Conference (DIS'12) 816-817.

62. Will Odom, Selby, M., Sellen, A., Kirk, D., Banks, R., \& Regan, T. 2012. Photobox: on the design of a slow technology. In: Proceedings of the 2012 ACM Designing Interactive Systems Conference (DIS'12) 665-668.

63. Thomas A. Offit. 2014. Objects of Time: How Things Shape Temporality. American Anthropologist. https://doi.org/10.1111/aman.1208 
64. Kenton P. O'Hara, Michael Massimi, Richard Harper, Simon Rubensand Jessica Morris. 2014. Everyday dwelling with WhatsApp, In: Proceedings of the 17th ACM Conference on Computer Supported Cooperative Work and Social Computing (CSCW'17) 1-13

65. Jackie O'Neill, Anupama Dhareshwar and Srihari H. Muralidhar. 2017. Working Digital Money into a Cash Economy: The Collaborative Work of Loan Payment. Journal Computer Supported Cooperative Work and Social Computing 26, 733-768 https://doi.org/10.1007/s10606017-9289-6

66. Wanda J Orlikowski and JoAnne Yates. 2002. It's About Time: Temporal Structuring in Organizations, Organization Science. 13(6): 684700

67. Oxfam Australia, Climate Change www.oxfam.org.au/what-we-do/climate-justice/climate-change-action/).

68. Oxfam Australia, Disaster Risk Reduction, www.oxfam.org.au/what-we-do/emergencies/disaster-risk-reduction/)

69. Oxfam Australia, International Crisis Fund https://secure.oxfam.org.au/donate/international-crisis-fund

70. Oxfam Australia, Keep Families Together www.oxfam.org.au/tag/families-together/

71. Oxfam Australia, Refugees: www.oxfam.org.au/what-we-do/emergencies/refugees/

72. Mark Perry and Jennifer Ferreira. 2018. Moneywork: Practices of Use and Social Interaction around Digital and Analog Money. ACM Transactions on Computer Human Interaction 24(6) Article 41. DOI: https://doi.org/10.1145/3162082

73. Jennifer Preece, Helen Sharp and Yvonne Rogers. Interaction design: Beyond Human-Computer Interaction. John Wiley \& Sons, 2015.

74. Promise, platform for tracking impact of charitable donations www.promisegiving.com/

75. Larissa Pschetz \& Bastian, M. 2018. Temporal Design: Rethinking time in design. Design Studies, 56, $169-184$.

76. Larissa Pschetz, Kruakae Pothong and Chris Speed. 2019. Autonomous Distributed Energy Systems: Problematising the Invisible through Design, Drama and Deliberation. In: Proceedings of the 2019 Conference on Human Factors in Computing Systems (CHI'19). 1-14. DOI: https://doi.org/10.1145/3290605.3300617

77. Michel Rauchs, Andrew Glidden, Brian Gordon, Gina Pieters, Martino Recanatini, François Rostand, Kathryn Vagneur and Bryan Zhang 2018. Distributed Ledger Technology Systems. www.jbs.cam.ac.uk/faculty-research/centres/alternative-finance/publications/distributed-ledgertechnology-systems/

78. Madhu Reddy, Paul Dourish and Wanda Pratt. 2006. Temporality in medical work: time also matters. Journal of Computer Supported Cooperative Work 15 (1)29-53

79. Corina Sas and Irni Eliana Khairuddin. 2017. Design for trust: An exploration of the challenges and opportunities of bitcoin users. In: Proceedings of the 2017 Conference on Human Factors in Computing Systems (CHI'17) 6499-6510).

80. Sarah Sharma. 2014. In the Meantime: Temporality and Cultural Politics. Duke University Press,

81. Phoebe Sengers. 2011. What I learned on Change Islands: reflections on IT and pace of life. Interactions 18(2)40-48.

82. Stephen Tsung-Han Sher and Norman Makoto Su. 2019. Speedrunning for Charity: How Donations Gather Around a Live Streamed Couch. In: Proceedings of the 2019 ACM Conference on Computer Supported Cooperative Work and Social Computing (CSCW'19). DOI: https://doi.org/10.1145/3359150

83. Patrick C. Shih, Victoria Bellotti, Kyungsik Han and John M. Carroll. 2015. Unequal time for unequal value: Implications of differing motivations for participation in timebanking. In: Proceedings of the 33rd Conference on Human Factors in Computing Systems (CHI'15), 10751084.

84. Melanie Swan. 2016. Blockchain Temporality: Smart Contract Time Specifiability with Blocktime. In: Alferes J., Bertossi L., Governatori G., Fodor P., Roman D. (eds) Rule Technologies. Research, Tools and Applications. Rule ML 2016. Lecture Notes in Computer Science (9718). Springer, Cham. https://doi.org/10.1007/978-3-319-42019-6_12

85. Lana Swartz. 2020. New Money-How Payment Became Social Media. Yale University Press.

86. Ella Tallyn, Joe Revans, Evan Morgan and Dave Murray-Rust. 2020. GeoPact: Engaging Publics in Location-aware Smart Contracts through Technological Assemblies. In: Proceedings of the 2020 Designing Interactive Systems Conference (DIS'20). 799-811. DOI: https://doi.org/10.1145/3357236.3395583

87. Ella Tallyn, Larissa Pschetz, Rory Gianni, Chris Speed and Chris Elsden. 2018. Exploring Machine Autonomy and Provenance Data in Coffee Consumption: A Field Study of Bitbarista. In: Proceedings of the 2018 ACM Conference on Computer Supported Cooperative Work and Social Computing (CSCW'18) Article 170 DOI: https://doi.org/10.1145/3274439

88. Katie G. Tanaka and Amy Voida. 2016. Legitimacy Work: Invisible Work in Philanthropic Crowdfunding. In: Proceedings of the 2016 Conference on Human Factors in Computing Systems (CHI'16) 4550-4561. DOI: https://doi.org/10.1145/2858036.2858110

89. Jennyfer Lawrence Taylor, Alessandro Soro, Paul Roe, Anita Lee Hong and Margot Brereton. 2017. Situational when: Designing for time across cultures. In: Proceedings of the 2017 Conference on Human Factors in Computing Systems (CHI'17) 6461-6474.

90. Ludwig Trotter, Mike Harding, Peter Shaw, Nigel Davies, Chris Elsden, Chris Speed, John Vines, Aydin Abadi, Josh Hallwright. 2020. Smart Donations: Event-Driven Conditional Donations Using Smart Contracts On The Blockchain. In: Proceedings of Australiasian Conference for Human Computer Interaction. (OzCHI'20) Australia ACM 
91. John Vines, Paul Dunphy and Andrew Monk. 2014. Pay or delay: the role of technology when managing a low income. In: Proceedings of the 2014 Conference on Human Factors in Computing Systems (CHI'14) 501-510. DOI: https://doi.org/10.1145/2556288.2556961

92. Amy Voida. 2014. A Case for Philanthropic Informatics. In: Saeed S. (eds) User-Centric Technology Design for Nonprofit and Civic Engagements. Public Administration and Information Technology, vol 9. Springer, Cham. https://doi.org/10.1007/978-3-319-05963-1_1

93. Amy Voida, Ellie Harmon, Willa Weller, Aubrey Thornsbury, Ariana Casale, Samuel Vance, Forrest Adams, Zach Hoffman, Alex Schmidt, Kevin Grimley, Luke Cox, Aubrey Neeley and Christopher Goodyear. 2017. Competing Currencies: Designing for Politics in Units of Measurement. In: Proceedings of the 2017 ACM Conference on Computer Supported Cooperative Work and Social Computing (CSCW'17). 847-860. DOI: https://doi.org/10.1145/2998181.2998209

94. Dhaval Vyas, Stephen Snow, Paul Roe and Margot Brereton. 2016. Social Organization of Household Finance: Understanding Artful Financial Systems in the Home. In: Proceedings of the 19th ACM Conference on Computer-Supported Cooperative Work \& Social Computing (CSCW'16) 1777-1789. DOI: https://doi.org/10.1145/2818048.2819937

95. Judy Wajcman 2019. How silicon valley sets time. New Media \& Society 21(6): 1272-1289.

96. Yang Wang and Scott D. Mainwaring. 2008. Human-Currency Interaction: learning from virtual currency use in China. In: Proceedings of the 2008 Conference on Human Factors in Computing Systems (CHI'08) 25-28. DOI: https://doi.org/10.1145/1357054.1357059

97. George Willis and Emmanouil Tranos. 2020. Using 'Big Data'to understand the impacts of Uber on taxis in New York City. Travel Behaviour and Society 22: 94-107.

98. Chi-Hsien Yen, Yi-Chieh Lee and Wai-Tat Fu. 2018. Visible Hearts, Visible Hands: A Smart Crowd Donation Platform. In 23rd International Conference on Intelligent User Interfaces (IUI'18). 385-395. DOI: https://doi.org/10.1145/3172944.3172971

99. Mert Yildiz and Aykut Coşkun. 2020. Time Perceptions as a Material for Designing New Representations of Time. In Extended Abstracts of the 2020 Conference on Human Factors in Computing Systems (CHI-EA'20), 1-7.

100. V.A Zelizer. 1989. The social meaning of money: special monies. American Journal of Sociology, 95(2) $342-377$. 